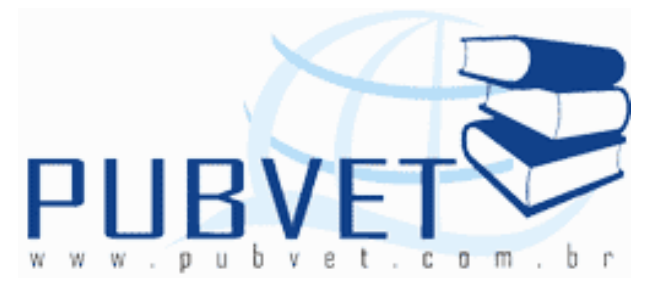

PUBVET, Publicações em Medicina Veterinária e Zootecnia.

\title{
Avaliação morfológica das estruturas ovarianas em fêmeas bovinas zebuínas durante o ciclo estral
}

\author{
Stephanie Mayra Pacifico de Souza ${ }^{1}$, Reginaldo da Silva Fontes ${ }^{2}$, Luis Fonseca \\ Matos $^{2}$, Celia Raquel Quirino ${ }^{2}$ \\ ${ }^{1}$ Aluna do Programa de Pós-Graduação em Ciência Animal. Universidade \\ Estadual do Norte Fluminense. \\ 2 Professores doLaboratório de Reprodução e Melhoramento Genético Animal, \\ Universidade Estadual do Norte Fluminense. Campos dos Goytacazes-RJ, \\ Brasil.
}

\section{Resumo}

O objetivo do presente estudo foi avaliar os aspectos morfométricos, ultraestruturais e histológicos das estruturas presentes nos ovários de fêmeas zebuínas. Foram utilizadas dez fêmeas bovinas. Nas fêmeas que foram sincronizadas, seguiu-se o protocolo convencional utilizado na técnica de inseminação artificial em tempo fixo (IATF). Os ovários foram avaliados com auxílio do ultrassom antes da sincronização e no dia da cirurgia. No dia 0 do ciclo estral, dois animais foram ovariectomizados, sendo que os demais passaram pelo mesmo processo nos respectivos dias: D5, D11, D14 e D19. Na avaliação macroscópica todas as estruturas foram consideradas. Os ovários tiveram os seus eixos máximos aferidos. Para as técnicas de histologia todos os ovários foram processados e as lâminas avaliadas. Ao exame ultrassonográfico, 
SOUZA, S.M.P. et al. Avaliação morfológica das estruturas ovarianas em fêmeas bovinas zebuínas durante o ciclo estral. PUBVET, Londrina, V. 8, N. 7, Ed. 256, Art. 1695, Abril, 2014.

constatou-se que a média do comprimento e da largura dos ovários não tiveram ampla variação, além de três dos animais terem apresentado corpo lúteo no ovário direito. Após a ovariectomia a mensuração do comprimento e largura dos ovários também foi realizada concluindo-se que não há uma diferença significativa entre a mensuração morfométrica das fêmeas em anestro e ciclando. Histologicamente, as estruturas encontradas nos ovários das vacas diferem-se somente pela quantidade de folículos primordiais.

Palavras-chave: Ovariectomia; Morfometria; Ultrassonografia; Histologia.

\title{
Morphological description of ovarian structures in zebu cows during the estrous cycle
}

\begin{abstract}
The aim of this study was to evaluate aspects morphometric, ultrastructural and histological structures present in the ovaries of female zebu. We used ten cows. In females that were synchronized, followed the standard protocol used in the technique of fixed time artificial insemination (FTAI). The ovaries were evaluated before synchronization and the day of surgery with the aid of ultrasound. On day 0 of the estrous cycle, two animals were ovariectomized, while the others went through the same process in their days: D5, D11, D14 and D19. The macroscopic structures were all considered. The ovaries had their axes maximum measured. For histological techniques all ovaries were processed and slides evaluated. When ultrasound was found that the average length and width of the ovaries did not have wide variation, and three animals have shown corpus luteum in the right ovary. After ovariectomy measuring the length and width of the ovaries was also performed and it was concluded that there is a significant difference between the morphometric measurement of cycling and anestrous females. Histologically, the structures found in the ovaries of cows differ only by the amount of primordial follicles.
\end{abstract}

Keywords: Ovariectomy; Morphometry; Ultrasonography; Histology. 
SOUZA, S.M.P. et al. Avaliação morfológica das estruturas ovarianas em fêmeas bovinas zebuínas durante o ciclo estral. PUBVET, Londrina, V. 8, N. 7, Ed. 256, Art. 1695, Abril, 2014.

\section{Introdução}

A maioria dos oócitos presentes no ovário ao nascimento não atinge a ovulação. Portanto, técnicas de reprodução assistida como a superovulação/TE (transferência de embriões) e PF/PIV (punção folicular/produção in vitro de embriões) têm sido desenvolvidas e aperfeiçoadas a fim de maximizar o potencial reprodutivo de fêmeas superiores ou ameaçadas de extinção. Contudo, avanços nas técnicas de reprodução assistida requerem melhor entendimento da fisiologia ovariana. Apesar da enorme quantidade de informações produzidas durante as duas últimas décadas, o entendimento completo dos mecanismos controladores do desenvolvimento folicular ainda não foi atingido (BURATINI JR. et al., 2005), especialmente na raça Nelore, base do rebanho brasileiro (SENEDA \& BORDIGNON, 2007).

Nos bovinos, os ovários são geralmente ovais a aplanados lateralmente, medindo em media de 30 a $45 \mathrm{~mm}$ de comprimento; 15 a $20 \mathrm{~mm}$ de largura e 20 a $28 \mathrm{~mm}$ de "profundidade". O peso dos ovários de vacas adultas varia de 15 a $20 \mathrm{~g}$ (LEAL, 2007) e apresentam, principalmente, as funções de produção de gametas e de hormônios, notadamente estrógenos e progesterona (NEVES et al., 2008).

O folículo é a unidade morfofuncional do ovário, sendo constituído por um oócito circundado por células somáticas (células da granulosa e tecais) (FIGUEIREDO et al., 2006; FIGUEIREDO et al., 2008). Desempenha duas funções principais, que são interdependentes: uma endócrina e a outra exócrina ou gametogênica. Nessa última função, o folículo é um elemento essencial para a manutenção da viabilidade oocitária, para assegurar o crescimento e a maturação de oócitos primários ou imaturos e, finalmente, para liberar um oócito maturado no processo de ovulação (FIGUEIREDO et al., 2008).

Dependendo da ausência ou presença de antro (cavidade repleta de líquido folicular circundando o oócito, e presente nos estádios finais de desenvolvimento do folículo ovariano), os folículos ovarianos são classificados em pré-antrais ou antrais, respectivamente (SANTOS et al., 2008). Os folículos 
SOUZA, S.M.P. et al. Avaliação morfológica das estruturas ovarianas em fêmeas bovinas zebuínas durante o ciclo estral. PUBVET, Londrina, V. 8, N. 7, Ed. 256, Art. 1695, Abril, 2014.

pré-antrais são constituídos pelos folículos primordiais, intermediários, primários e secundários. Podem ser diferenciados entre si pela forma e pelo número de camadas de células da granulosa que circundam o oócito imaturo (FIGUEIREDO et al., 2008). Os folículos antrais compreendem os folículos terciários (subordinados e dominantes) e pré-ovulatórios. Os folículos préovulatórios apresentam todos os componentes presentes nos folículos terciários, contudo o oócito apresentar-se-á maturo e no estádio final do desenvolvimento folicular (SANTOS et al., 2008)

O desenvolvimento folicular ovariano é um processo dinâmico caracterizado pela emergência de ondas sucessivas (FIGUEIREDO et al., 2000). Cada onda dura cerca de 8 a 10 dias e é dependente da duração do corpo lúteo durante o ciclo estral (MELO, 2007).

A elevação nas concentrações plasmáticas de FSH constitui o estímulo necessário para o recrutamento e emergência da onda folicular (duas ou três por ciclo estral em bovinos) (FERNANDES, 2008). Na espécie bovina, de forma predominante, apenas um folículo é selecionado e passa a exercer dominância sobre os demais que compõem a onda folicular (MACHADO, 2008). Devido a secreção de estradiol e inibina, os folículos em crescimento causam redução dos níveis circulantes de $\mathrm{FSH}$, que se tornam insuficientes para a manutenção do crescimento dos folículos subordinados (FERNANDES, 2008). Quando o folículo dominante está presente no momento da regressão luteínica, este culmina com a ovulação (MELO, 2009). A diminuição nos níveis plasmáticos de progesterona permite o aumento dos níveis de estrógeno e consequentemente de LH (MACEDO, 2008). Após a ovulação, as células que permanecem no folículo rompido proliferam e formam o corpo lúteo $(C L)$, cuja função nesse caso, domina o ciclo do dia 4 até cerca do dia 17 (MACEDO, 2008).

$\mathrm{Na}$ ovulação ocorre a ruptura da membrana folicular e a expulsão do oócito. Imediatamente após a ovulação a parede do folículo ovulado é colapsada e a cavidade invadida por linfa e sangue provenientes dos capilares. Esse conjunto de componentes juntamente com as células remanescentes do folículo ovulado formarão o CL (MARTIN \& FERREIRA, 2009). 
A avaliação do $\mathrm{CL}$ fornece informações importantes sobre o estado reprodutivo da fêmea e possibilita a adequação de procedimentos de manipulação ou sincronização do ciclo estral (LEAL, 2007). Sendo assim, Ireland et al. (1980), levando em consideração: coloração externa e interna, presença ou não de vasos sanguíneos na superfície, presença de epitélio recobrindo o ponto de ruptura, grau de protusão e tamanho, criou quatro estágios de classificação de desenvolvimento desta estrutura.

\section{Materiais e métodos}

\section{Animais e local do experimento}

As etapas do experimento foram realizadas no LRMGA (Laboratório de Reprodução e Melhoramento Genético animal) e no LSA (Laboratório de Sanidade Animal) localizados na UENF, Universidade Estadual do Norte Fluminense, que se encontra no município de Campos dos Goytacazes (RJ).

Foram utilizadas dez fêmeas bovinas azebuadas de 2 a 3 anos e sem registro genealógico. Tendo um peso médio maior do que $380 \mathrm{Kg} \mathrm{e}$ apresentando escore de condição corporal $(E C C) \geq 3$ (escala de $1=$ muito magra a 5 = muito gorda), com exceção de dois animais que apresentaram ECC $<2$, caracterizando assim, o ovário de uma vaca em anestro nutricional.

\section{Sincronização do ciclo estral}

Em todas as fêmeas que foram sincronizadas, seguiu-se o protocolo convencional utilizado na técnica de Inseminação Artificial em Tempo Fixo (IATF) (Figura 1). 


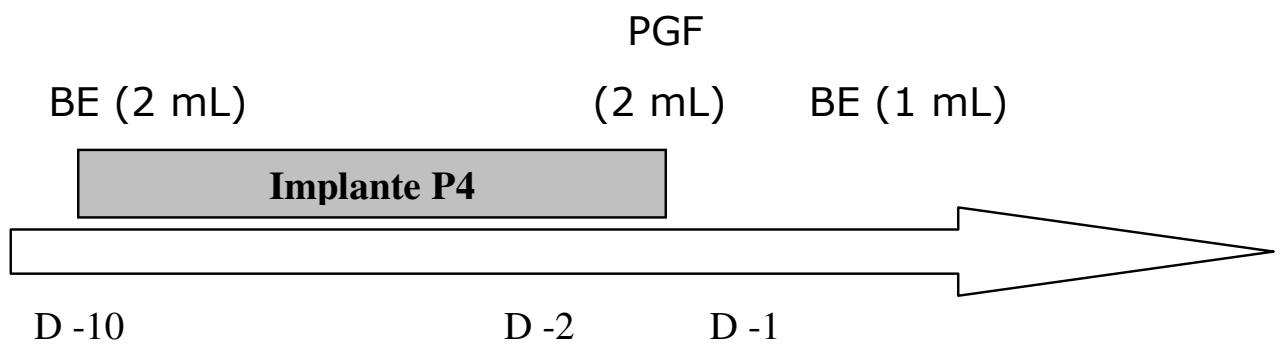

Figura 1: Protocolo convencional de IATF.

\section{Avaliação dos ovários com o auxílio do ultrassom}

A ultrasonografia trans-retal foi realizada com o auxílio de um ultrassom da marca "Pie Medical Falcon 100", equipado com transdutor linear 8,0 MHz. Os ovários foram avaliados antes da sincronização e no dia da cirurgia, sendo mensurados o comprimento e a largura, além de realizada a observação de suas estruturas e medida da maior estrutura presente (Corpo Lúteo ou folículo).

\section{Cirurgia de ovariectomia}

No dia 0 do ciclo estral, dois animais foram ovariectomizados, sendo que as demais passaram pelo mesmo processo de duas em duas nos respectivos dias: D5, D11, D14 e D19 (Fig. 2).

DIA DO CICLO ESTRAL

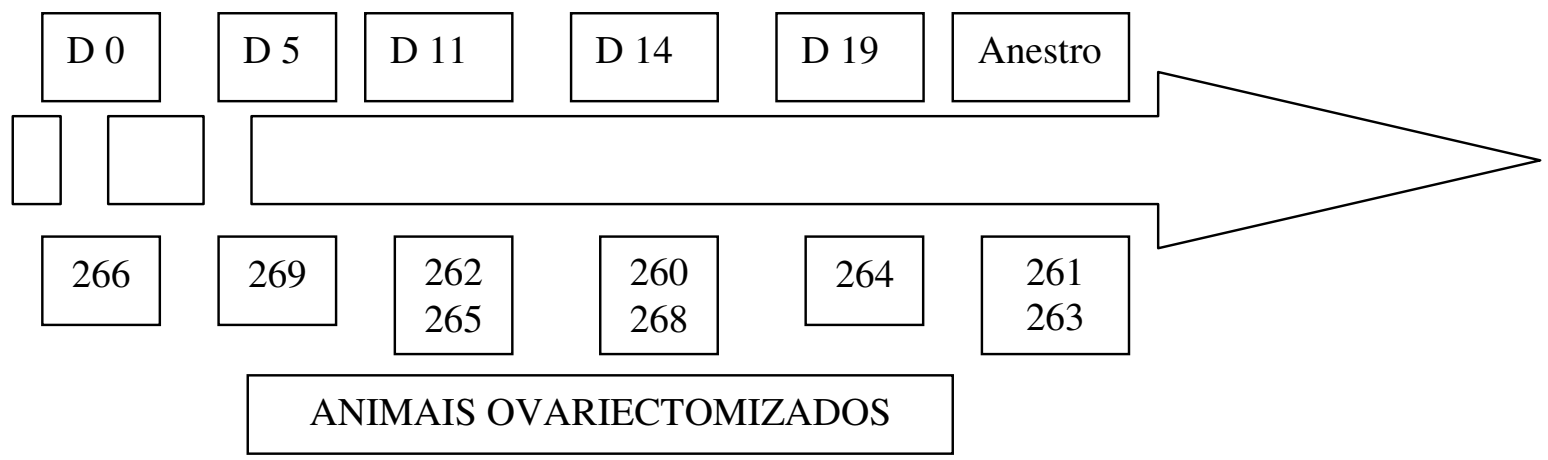

Figura 2: Cronograma da ovariectomia. 
Anteriormente à cirurgia, os animais ficaram pelo menos 24 horas em jejum. A analgesia para a cirurgia se procedeu da seguinte forma: para se conseguir a tranquilização do animal foi aplicado cerca de $0,5 \mathrm{~mL}$ de Cloridrato de Xilazina por via intramuscular (IM) e para alcançar a anestesia foram associados três formas de aplicação de dois fármacos distintos, a epidural com $2 \mathrm{~mL}$ de Cloridrato de Lidocaína 2\%, $5 \mathrm{~mL}$ de Cloridrato de Cetamina 10\% por via IM, aplicação no local da incisão em L invertido de Cloridrato de Lidocaína $2 \%$.

A ovariectomia foi realizada cirurgicamente pelo flanco esquerdo. No acesso cirúrgico foi realizada uma incisão de cerca de 10 - 15 centímetros.

Depois de realizada todas as incisões e a retirada de ambos os ovários (esquerdo e direito), foi efetuada a sutura das estruturas, sendo que os tecidos internos foram suturados em " $x$ " utilizando-se fio absorvível (Categute 3 ou 4) e a pele com fio de nylon 0,60 mm com sutura de "reverdin".

Os ovários retirados passaram pela avaliação da morfometria, onde foi mensurado com o auxílio de uma régua o comprimento e a largura e, com o auxílio de uma câmera digital, imagens foram feitas das estruturas externas.

\section{Avaliação macroscópica dos ovários}

Nesta fase do experimento foram consideradas todas as estruturas visíveis na superfície do ovário. Para possibilitar o trabalho com os ovários, os mesmos foram lavados com solução fisiológica e acomodados em uma superfície plana para mensuração e contagem do número de folículos superficiais bem como o de CL.

Os ovários tiveram os seus eixos máximos aferidos com o auxílio de uma régua graduada e os respectivos dados anotados.

Nessa etapa, também foi comparada a classificação da fase do ciclo estral em que a fêmea se encontrava, tendo como base a classificação do $C L$, quando presente, segundo Ireland (1980). 


\section{Histologia ovariana: fixação dos ovários}

Depois de toda análise macroscópica, os ovários foram acondicionados em frascos plásticos individualizados previamente identificados e contendo solução fixadora de formol a $10 \%$.

Os ovários foram processados no LSA da UENF e incluídos em blocos de parafina. Para cada bloco foi efetuado cortes de $4 \mu \mathrm{m}$ de espessura, que foi fixado em lâmina, corado com Hematoxilina e Eosina e coberto com lamínula colada com Bálsamo do Canadá.

Por meio do microscópio de luz da marca Nikon, com aumento de 40 vezes, as lâminas contendo os cortes ovarianos foram avaliadas e imagens foram feitas com auxílio de uma câmera digital.

\section{Resultados e discussão}

\section{1-Avaliados com o auxílio do ultrassom}

Previamente à realização da sincronização, oito dos animais que estavam no experimento, animais estes que estavam ciclando, passaram por avaliação ultrasonográfica, onde foram mensurados o comprimento e a largura de ambos os ovários, além da observação das estruturas ovarianas e obtenção do diâmetro do folículo dominante e/ou CL quando presentes.

Ao realizar as medidas propostas (comprimento e largura) (Fig. 3 e Tab. 1), observou-se que a média para o comprimento do ovário direito foi de 27,2 $\mathrm{mm}$, sendo que a maior medida foi de $34,2 \mathrm{~mm}$ e a menor de $19,7 \mathrm{~mm}$ e para o ovário esquerdo a média foi de $22,2 \mathrm{~mm}$, sendo que a maior medida foi de $30,9 \mathrm{~mm}$ e a menor de $11,3 \mathrm{~mm}$. Já a largura média do ovário direito foi de $14,3 \mathrm{~mm}$, sendo que a maior medida foi de $20,8 \mathrm{~mm}$ e a menor de $8,7 \mathrm{~mm}$ e para o ovário esquerdo a média foi de $13,9 \mathrm{~mm}$, sendo que a maior medida foi de $21,5 \mathrm{~mm}$ e a menor de $9,6 \mathrm{~mm}$. 

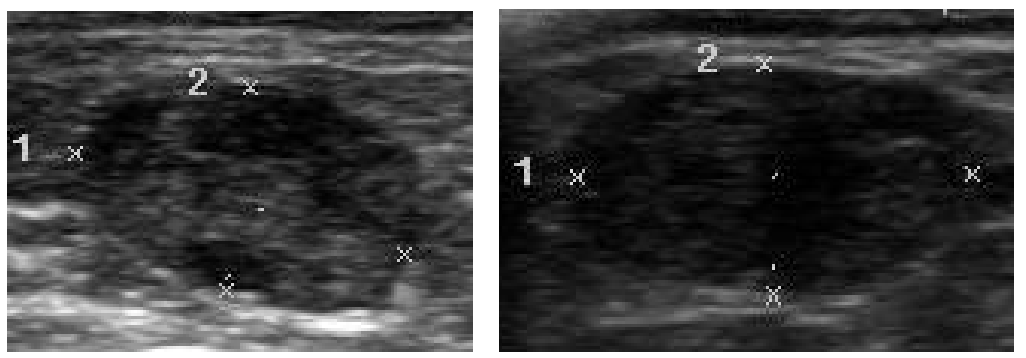

Figura 3: Maneira como foi realizada as medidas propostas, onde 1 é o comprimento e 2 é a largura.

Tabela 1: Medidas ultrasonográficas dos ovários das vacas.

\begin{tabular}{ccccc}
\hline & \multicolumn{2}{c}{ Ovário direito } & \multicolumn{2}{c}{ Ovário esquerdo } \\
\hline$N^{\circ}$ vaca & Comprimento & Largura & Comprimento & Largura \\
260 & $(\mathrm{~mm})$ & $(\mathrm{mm})$ & $(\mathrm{mm})$ & $(\mathrm{mm})$ \\
262 & 19,7 & 11,1 & 11,3 & 9,6 \\
263 & 30,3 & 17,0 & 30,9 & 17,1 \\
264 & 23,6 & 16,9 & 20,0 & 14,3 \\
265 & 25,0 & 12,6 & 22,5 & 13,4 \\
266 & 34,2 & 20,8 & 30,3 & 21,5 \\
268 & 27,6 & 13,3 & 17,6 & 10,5 \\
269 & 23,9 & 8,7 & 14,8 & 10,9 \\
Média & 33,1 & 14,2 & 30,7 & 13,8 \\
medidas & 27,2 & 14,3 & 22,3 & 13,9 \\
\hline
\end{tabular}

Menor comprimento dos ovários (direito e esquerdo); Menor largura dos ovários (direito e esquerdo); Maiores medidas dos ovários (direito e esquerdo).

Outro resultado obtido através da análise ultrassonográfica foi o das estruturas presentes no ovário, antes da sincronização e no momento da cirurgia de cada animal. 
SOUZA, S.M.P. et al. Avaliação morfológica das estruturas ovarianas em fêmeas bovinas zebuínas durante o ciclo estral. PUBVET, Londrina, V. 8, N. 7, Ed. 256, Art. 1695, Abril, 2014.

As estruturas encontradas nos ovários das fêmeas antes da sincronização seguem-se na tabela 2. Observar que somente um animal (263) apresentou CL e que a maioria das vacas encontrava um ovário polifolicular (Figura 4).

Tabela 2: Estruturas presentes no ovário antes da sincronização.

\begin{tabular}{|c|c|c|c|c|c|c|}
\hline & & Ovário direito & & & Ovário esquerdo & \\
\hline $\begin{array}{r}\mathrm{N}^{\circ} \\
\text { vaca }\end{array}$ & $\begin{array}{l}N^{\circ} \text { de } \\
\text { folículos }\end{array}$ & $\begin{array}{c}\text { Diâmetro }(\mathrm{mm}) \text { da } \\
\text { maior } \\
\text { estrutura }\end{array}$ & $C L$ & jo de folículos & $\begin{array}{c}\text { Diâmetro }(\mathrm{mm}) \mathrm{da} \\
\text { maior } \\
\text { estrutura }\end{array}$ & $C L$ \\
\hline 260 & $>4$ & 10,2 & $\mathrm{n}$ & 1 & 5,2 & $n$ \\
\hline 262 & PF & 11,5 & $\mathrm{n}$ & PF & não mensurável & $\mathrm{n}$ \\
\hline 263 & $>5$ & 11,7 & $\mathrm{n}$ & $>4$ & $C L=12,3$ & s \\
\hline 264 & PF & 5,8 & $\mathrm{n}$ & $>4$ & 9,5 & $n$ \\
\hline 265 & PF & não mensurável & $\mathrm{n}$ & PF & não mensurável & $\mathrm{n}$ \\
\hline 266 & $>10$ & 10,1 & $n$ & PF & não mensurável & $\mathrm{n}$ \\
\hline 268 & PF & não mensurável & $\mathrm{n}$ & $>6$ & 4,7 & $\mathrm{n}$ \\
\hline 269 & PF & 6,2 & $\mathrm{n}$ & PF & 10,8 & $\mathrm{n}$ \\
\hline
\end{tabular}

CL: corpo lúteo; PF: polifolicular, n: não; s: sim.
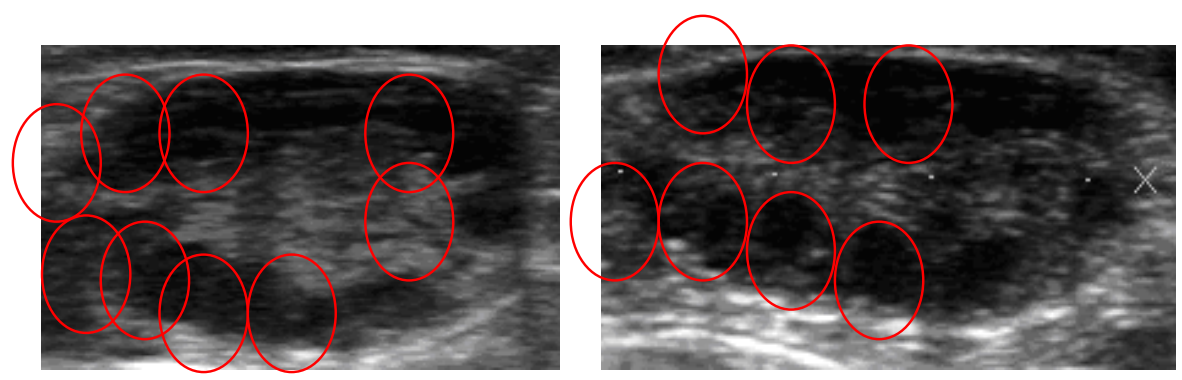

Figura 4: Ovários polifoliculares.

\section{2- Avaliações ultrassonográficas comparativas: ovulação Vs. não ovulação VS. anestro}

Dentre os animais que participaram do experimento, somente três ovularam, cinco não ovularam e duas estavam em anestro nutricional. Por isso, torna-se necessário realizar uma comparação das estruturas 
SOUZA, S.M.P. et al. Avaliação morfológica das estruturas ovarianas em fêmeas bovinas zebuínas durante o ciclo estral. PUBVET, Londrina, V. 8, N. 7, Ed. 256, Art. 1695, Abril, 2014.

ultrasonográficas encontradas nesses animais durante as diferentes fases do experimento, contudo, é importante destacar que os animais em anestro não foram sincronizados e não passaram pela avaliação ultrasonográfica dos ovários antes da sincronização dos outros animais.

Além das estruturas encontradas, quando possível, também foram relatadas as medidas obtidas dos ovários com o auxílio do ultrassom. Todos esses dados foram descritos de forma demonstrativa, onde foi escolhido o animal mais representativo de todas as situações; encontram-se nas figuras 5, 6,7 .

Reparar que antes da sincronização os ovários das fêmeas que ovularam e das que não ovularam se encontravam polifoliculares e/ ou com folículos em fase de seleção e dominância; contudo as vacas em anestro apresentaram um ovário com poucas estruturas ultrasonográficas, possuindo apenas algum folículo de tamanho considerável.

O comprimento do ovário das vacas em anestro não foi mensurado ultrasonograficamente, mas aparentemente se mostram menores do que as demais vacas; entretanto, as outras fêmeas não apresentaram diferença significativa entre o tamanho dos ovários, quando comparado os ovários da mesma fêmea e também quando comparado com os das outras fêmeas.

Após a sincronização, as fêmeas que ovularam apresentaram o CL no ovário direito e o ovário esquerdo mostrou ser correspondente com a fase do ciclo estral em que se encontra; contudo, as fêmeas que não ovularam e também as que se encontram em anestro, continuaram apresentando uma dinâmica folicular anovulatória; Molina (2005) relata que os sinais característicos desse estado são ovários pequenos devido à ausência de corpo lúteo ou de folículos com tamanho de ovulação. Contudo, avaliações diárias com ultra-som dos ovários pequenos dessas vacas em condição anovulatória demonstraram que o crescimento folicular continua em um padrão dinâmico de onda. Entretanto, sabe-se que os ovários com crescimento dos folículos até a divergência também se caracterizam por serem pequenos. 
SOUZA, S.M.P. et al. Avaliação morfológica das estruturas ovarianas em fêmeas bovinas zebuínas durante o ciclo estral. PUBVET, Londrina, V. 8, N. 7, Ed. 256, Art. 1695, Abril, 2014.

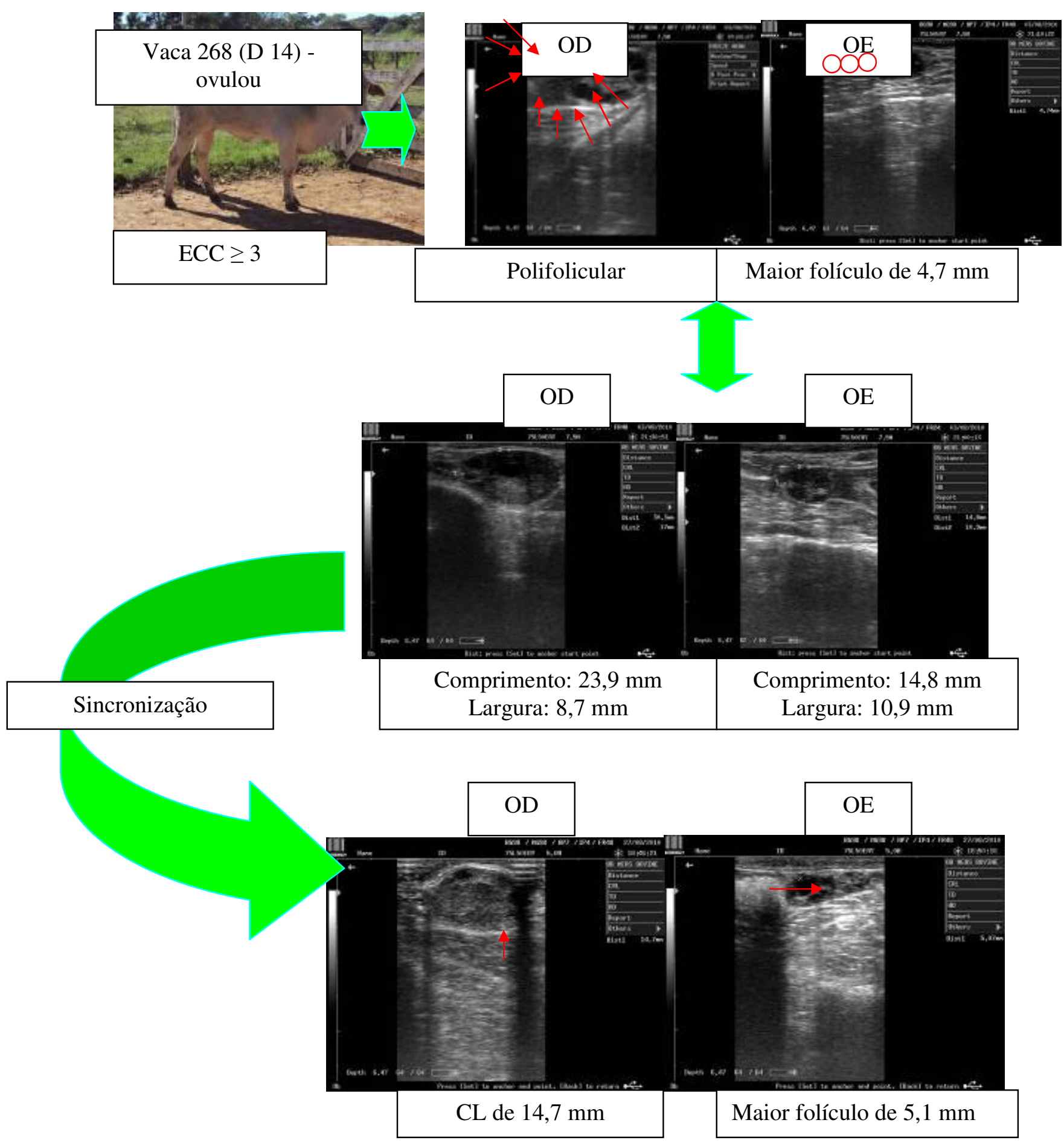

Figura 5: Estruturas ultrasonográficas encontradas na vaca que ovulou. 
SOUZA, S.M.P. et al. Avaliação morfológica das estruturas ovarianas em fêmeas bovinas zebuínas durante o ciclo estral. PUBVET, Londrina, V. 8, N. 7, Ed. 256, Art. 1695, Abril, 2014.
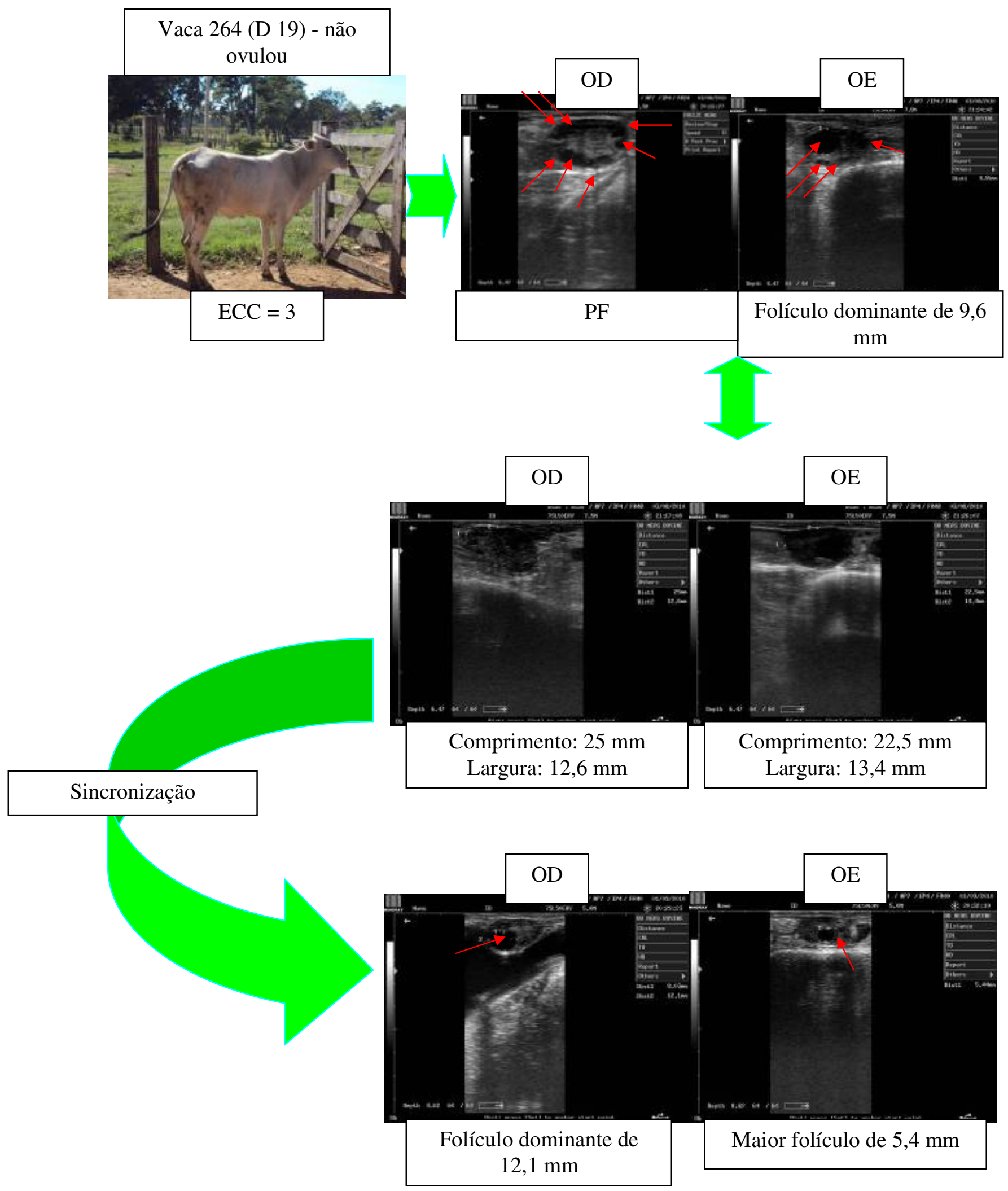

Figura 6: Estruturas ultrasonográficas encontradas na vaca que não ovulou. 


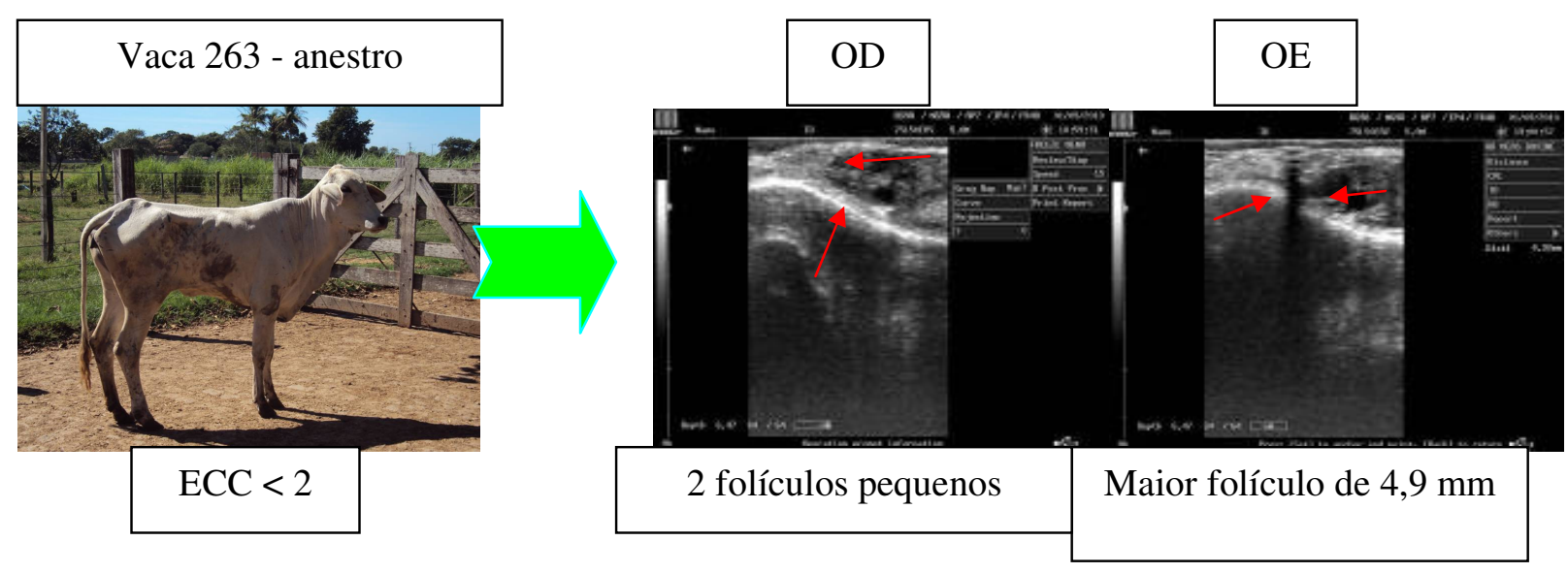

Figura 7: Estruturas ultrasonográficas encontradas na vaca em anestro.

\section{3- Achados macroscópicos}

Após a cirurgia de ovariectomia, a mensuração das medidas do comprimento e largura dos ovários das vacas do experimento foi realizada. Nas tabelas 3 e 4 segue-se a descrição dos valores obtidos e na figura 8 mostra como foi realizado essas medidas.

Tabela 3: Medidas ovarianas das vacas sincronizadas após ovariectomia.

\begin{tabular}{|c|c|c|c|c|c|}
\hline \multirow[b]{2}{*}{ jo vaca } & \multirow{2}{*}{$\begin{array}{l}\text { Dia do } \\
\text { ciclo } \\
\text { estral }\end{array}$} & \multicolumn{2}{|l|}{ OD } & \multicolumn{2}{|l|}{$\mathrm{OE}$} \\
\hline & & $\begin{array}{l}\text { Comprimento } \\
(\mathrm{Cm})\end{array}$ & $\begin{array}{l}\text { Largura } \\
\text { (Cm) }\end{array}$ & $\begin{array}{l}\text { Comprimento } \\
(\mathrm{Cm})\end{array}$ & $\begin{array}{c}\text { Largura } \\
(\mathrm{Cm})\end{array}$ \\
\hline 266 & D 0 & 2,5 & 2,0 & 3,0 & 1,5 \\
\hline 269 & D 5 & 3,5 & 2,5 & 4,0 & 2,5 \\
\hline 262 & D 11 & 3,5 & 2,5 & 3,5 & 2,5 \\
\hline 265 & D 11 & 4,0 & 3,0 & 4,0 & 2,5 \\
\hline 260 & D 14 & 2,5 & 2,0 & 2,5 & 1,5 \\
\hline 268 & D 14 & 2,5 & 2,0 & 2,0 & 1,5 \\
\hline 264 & D 19 & 3,0 & 2,0 & 3,0 & 2,0 \\
\hline
\end{tabular}


SOUZA, S.M.P. et al. Avaliação morfológica das estruturas ovarianas em fêmeas bovinas zebuínas durante o ciclo estral. PUBVET, Londrina, V. 8, N. 7, Ed. 256, Art. 1695, Abril, 2014.

Tabela 4: Medidas ovarianas das vacas em anestro, denominadas unha e magrela.

\begin{tabular}{|c|c|c|c|c|c|}
\hline & Fase ciclo & OD & & $\mathrm{OE}$ & \\
\hline ca & estral & $\begin{array}{l}\text { Comprimento } \\
\text { (Cm) }\end{array}$ & $\begin{array}{l}\text { Largura } \\
\qquad(\mathrm{Cm})\end{array}$ & $\begin{array}{l}\text { Comprimento } \\
\qquad(\mathrm{Cm})\end{array}$ & $\begin{array}{l}\text { Largura } \\
\qquad(\mathrm{Cm})\end{array}$ \\
\hline 261 & anestro & 2,5 & 2,0 & 3,0 & 2,0 \\
\hline 263 & anestro & 2,0 & 2,0 & 2,0 & 2,0 \\
\hline
\end{tabular}

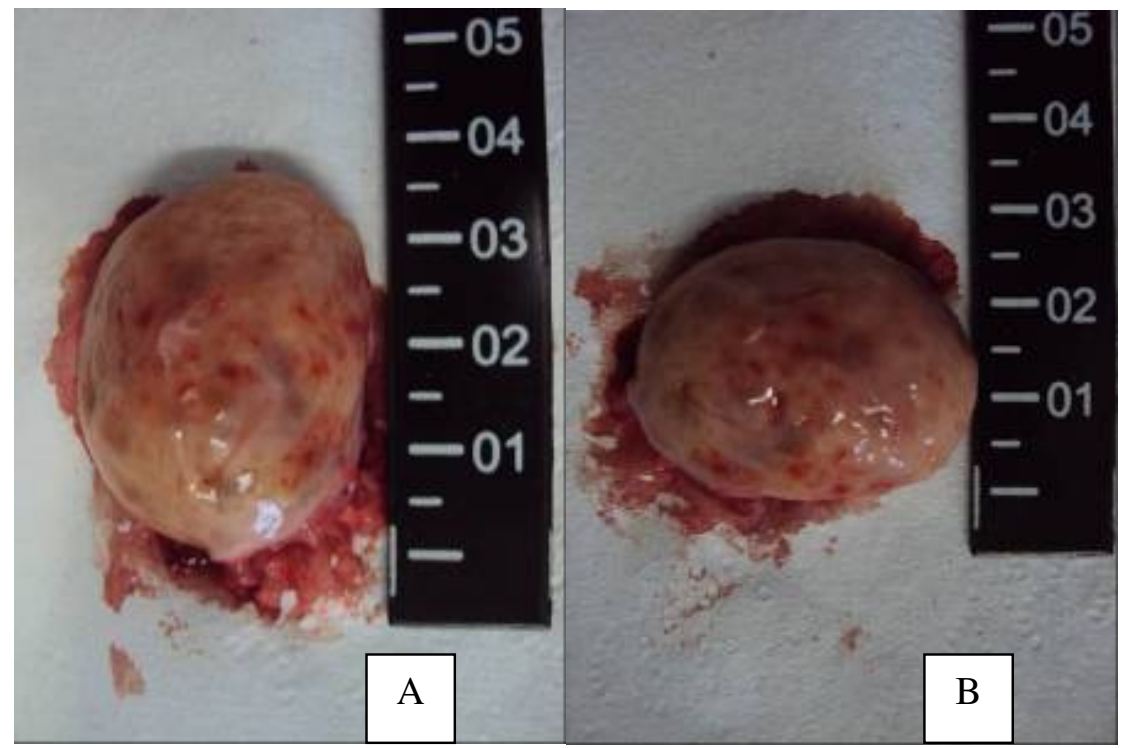

Figura 8: Maneira utilizada para mensuração do comprimento (A) e largura (B) dos ovários retirados das vacas por método cirúrgico.

A média para o comprimento do ovário direito das fêmeas sincronizadas foi de $3,1 \mathrm{~cm}$ e a média para a largura foi de $2,3 \mathrm{~cm}$. Já para o ovário esquerdo, a média do comprimento foi de $3,1 \mathrm{~cm}$ e a média da largura foi de 2,0 cm. Na literatura, Chacur et al. (2009), relata que os resultados obtidos para vacas zebus foram de medidas de $2,57 \pm 0,70 \mathrm{~cm}$ de comprimento para o ovário esquerdo e 2,62 $\pm 0,54 \mathrm{~cm}$ para o direito; contudo, os resultados obtidos para a largura foram de 1,95 cm para o lado esquerdo e 1,83 cm para 
SOUZA, S.M.P. et al. Avaliação morfológica das estruturas ovarianas em fêmeas bovinas zebuínas durante o ciclo estral. PUBVET, Londrina, V. 8, N. 7, Ed. 256, Art. 1695, Abril, 2014.

o direito. Lembrando que as medidas encontradas nos ovários das fêmeas em anestro também corroboram com os resultados obtidos por Chacur et al.

Além disso, outros aspectos foram observados macroscopicamente: a morfologia do ovário, como coloração, consistência e formato, além do número de estruturas superficiais (resumidos na Tabela 5 e 6).

Tabela 5: Estruturas superficiais presentes nos ovários das vacas sincronizadas.

\begin{tabular}{|c|c|c|c|c|c|}
\hline \multirow{2}{*}{$\begin{array}{c}\text { Dia do ciclo } \\
\text { estral } \\
\text { D } 0\end{array}$} & \multirow{2}{*}{$\begin{array}{c}\text { No vaca } \\
266\end{array}$} & \multicolumn{2}{|c|}{$\begin{array}{l}\mathrm{N}^{\circ} \text { folículos } \\
\text { presentes }\end{array}$} & \multirow{2}{*}{$\begin{array}{c}\text { Presença de folículo } \\
\text { dominante? } \\
+(\mathrm{OE})\end{array}$} & \multirow[t]{2}{*}{$\begin{array}{c}\text { Presença de } \\
\text { CL? }\end{array}$} \\
\hline & & OD & $\mathrm{OE}$ & & \\
\hline & & $>13$ & $>12$ & & \\
\hline \multirow[t]{2}{*}{ D 5} & $269 * * *$ & OD & OE & & \\
\hline & & $>35$ & $>33$ & & \\
\hline \multirow[t]{2}{*}{ D 11} & 265 & OD & OE & & $+(O D)$ \\
\hline & & $>20$ & $>25$ & & \\
\hline \multirow[t]{2}{*}{ D 11} & 262 & OD & OE & & \\
\hline & & $>26$ & $>25$ & & \\
\hline \multirow[t]{2}{*}{ D 14} & 260 & OD & OE & $+(\mathrm{OE})$ & $+(\mathrm{OD})$ \\
\hline & & $>8$ & $>5$ & & \\
\hline \multirow[t]{2}{*}{ D 14} & $268^{*}$ & OD & OE & & $+(\mathrm{OD}) * *$ \\
\hline & & danificado & $>11$ & & \\
\hline \multirow[t]{2}{*}{ D 19} & & OD & $\mathrm{OE}$ & $+(O D)$ & \\
\hline & 264 & $>5$ & $>9$ & & \\
\hline
\end{tabular}


SOUZA, S.M.P. et al. Avaliação morfológica das estruturas ovarianas em fêmeas bovinas zebuínas durante o ciclo estral. PUBVET, Londrina, V. 8, N. 7, Ed. 256, Art. 1695, Abril, 2014.

Tabela 6: Estruturas superficiais presentes no ovário das vacas em anestro.

\begin{tabular}{cccc}
\hline $\begin{array}{c}\text { Fase do } \\
\text { ciclo estral }\end{array}$ & Vaca & \multicolumn{2}{c}{ No folículos $^{\text {presentes }}$} \\
\hline Anestro & 261 & OD & OE \\
& & $>15$ & 7 \\
& & & \\
Anestro & 263 & OD & OE \\
& & 12 & 6 \\
\hline
\end{tabular}

Em se tratando da morfologia, os ovários apresentaram formato ovóide, coloração amarelada e consistência fibro-elástica, enfatizando, portanto, os resultados obtidos por Leal (2008).

Contudo, outra análise proposta foi a observação das características do corpo lúteo com posterior classificação da fase do ciclo estral em que o animal se encontra, sendo essa classificação baseada nas características de CL proposta por Ireland (1980). Os resultados obtidos e confrontados estão descritos na tabela 7.

Tabela 7: Classificação do ciclo estral: Ireland Vs. tratamento.

\begin{tabular}{ccc}
\hline Vacas com CL & $\begin{array}{c}\text { Classificação do ciclo } \\
\text { estral baseado em } \\
\text { Ireland } \\
260\end{array}$ & $\begin{array}{c}\text { Classificação do ciclo } \\
\text { estral baseado no } \\
\text { tratamento }\end{array}$ \\
265 & $\begin{array}{c}\text { (D 11-17) } \\
\text { CL em estádio 3 } \\
\text { (D 11-17) } \\
\text { CL rompido na } \\
\text { cirurgia }\end{array}$ & D 11 \\
& D 14 \\
\hline
\end{tabular}


SOUZA, S.M.P. et al. Avaliação morfológica das estruturas ovarianas em fêmeas bovinas zebuínas durante o ciclo estral. PUBVET, Londrina, V. 8, N. 7, Ed. 256, Art. 1695, Abril, 2014.

\section{4- Achados Histológicos}

Os resultados histológicos encontrados serão descritos na tabela 8 . Ressaltando que apenas dois animais apresentaram $\mathrm{CL}$, sendo essa estrutura descrita como células poliédricas com núcleo central redondo, citoplasma amplo, levemente eosinofílico, sem estroma, possui tênue vascularização e as células algumas vezes podem ser vacuolizadas (Figura 9 - a).

Tabela 8: Imagens obtidas através da histologia ovariana.

\begin{tabular}{ccccccccccccccc}
\hline $\begin{array}{c}\text { Dia do ciclo } \\
\text { estral }\end{array}$ & $\mathrm{N}^{\circ}$ & \multicolumn{1}{c}{$\mathrm{FP}$} & \multicolumn{1}{c}{$\mathrm{F}^{\circ}$} & $\mathrm{F} 2^{\circ}$ & $\mathrm{F} \mathrm{3} 3^{\circ}$ & $\mathrm{CL}$ & & $\mathrm{EH}$ \\
& & & $\mathrm{OD}$ & $\mathrm{OE}$ & $\mathrm{OD}$ & $\mathrm{OE}$ & $\mathrm{OD}$ & $\mathrm{OE}$ & $\mathrm{OD}$ & $\mathrm{OE}$ & $\mathrm{OD}$ & $\mathrm{OE}$ & $\mathrm{OD}$ & $\mathrm{OE}$ \\
D 0 & 266 & 4 & 5 & 4 & 4 & 3 & 1 & 2 & 3 & - & - & 8 & 7 \\
D 5 & 269 & 20 & 27 & 10 & 6 & 4 & 3 & 10 & 7 & - & - & 7 & 11 \\
D 11 & 265 & 16 & 56 & 5 & 11 & 1 & 3 & 5 & 7 & 1 & - & 5 & 7 \\
D 11 & 262 & 15 & 8 & 1 & 1 & 2 & 3 & 3 & 2 & - & - & 1 & 3 \\
D 14 & 260 & 3 & 9 & - & - & - & 1 & 1 & 1 & 1 & - & 1 & 1 \\
D 14 & 268 & 14 & 46 & 2 & 3 & 1 & 1 & 5 & 2 & - & - & 7 & 5 \\
D 19 & 264 & 8 & 20 & 2 & 1 & 2 & 3 & 2 & 5 & - & - & 11 & 7 \\
Anestro & 261 & 24 & 22 & 6 & 7 & 6 & 3 & 8 & 9 & - & - & 16 & 6 \\
Anestro & 263 & 112 & 60 & 17 & 12 & 6 & 4 & 6 & 7 & - & - & 10 & 11 \\
\hline
\end{tabular}

$\mathrm{FP}=$ folículo primordial; $\mathrm{F} 1^{\circ}=$ folículo primário; $\mathrm{F} 2^{\circ}=$ folículo

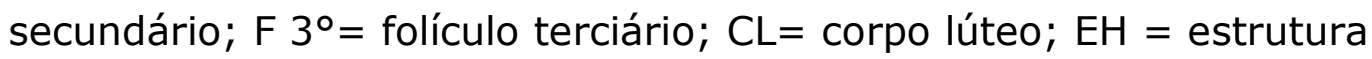
hialina.

Nos cortes histológicos foram encontradas estruturas hialinas (Figura 9 b) que são vistas em tecidos cicatriciais, entretanto, pelo motivo das vacas terem passado por três sessões de punção folicular guiada por ultrassom, não foi possível realizar a exata distinção da origem dessas estruturas, pois podem ser originadas da cicatriz formada após a perfuração do ovário ou podem ter 
origem da formação do corpo albicans (CA). Com isso, são necessários mais estudos para obter a exata origem desse tipo estrutural.

Em estudo realizado por Viana et al. (2003), a avaliação histopatológica demonstrou a presença de diferentes alterações morfológicas nos ovários, como pontos de perfuração na túnica albugínea, presença de áreas com hemorragia e infiltrados de células inflamatórias, e fibrose no estroma ovariano, associado a cicatrizes no trajeto da agulha. Foram observados folículos previamente aspirados apresentando hemorragia interna e graus variados de desorganização das camadas da parede folicular. Foi observada, também, a presença de áreas de tecido luteal ou de células luteais dispersas no estroma ovariano, provavelmente originadas da luteinização parcial de folículos cuja parede foi fragmentada pela punção.

Contudo, na figura 9 são demonstradas algumas estruturas encontradas nos cortes histológicos dos tecidos ovarianos.

\section{5- O ciclo estral e a ovulação}

Nesse experimento, das vacas que foram sincronizadas apenas três ovularam, entretanto, somente será realizada a análise comparativa de duas fêmeas, pois o $\mathrm{CL}$ do terceiro animal foi rompido durante os procedimentos cirúrgicos.

Como já mencionado nas discussões acima, a classificação do ciclo estral baseada nas características do CL propostas por Ireland (1980), realmente coincide com a etapa do ciclo estral que obtivemos através da sincronização, podendo ser uma referência para realizar essa classificação. Contudo, com os dados de que dispomos, outra análise de cunho comparativo se faz importante; por isso, com o auxílio das imagens obtidas durante o trabalho experimental, abaixo, será demonstrada toda uma sequência ilustrativa (Figura 10 e 11) com o intuito de analisar se o que foi encontrado é realmente o que é descrito na literatura. 
SOUZA, S.M.P. et al. Avaliação morfológica das estruturas ovarianas em fêmeas bovinas zebuínas durante o ciclo estral. PUBVET, Londrina, V. 8, N. 7, Ed. 256, Art. 1695, Abril, 2014.
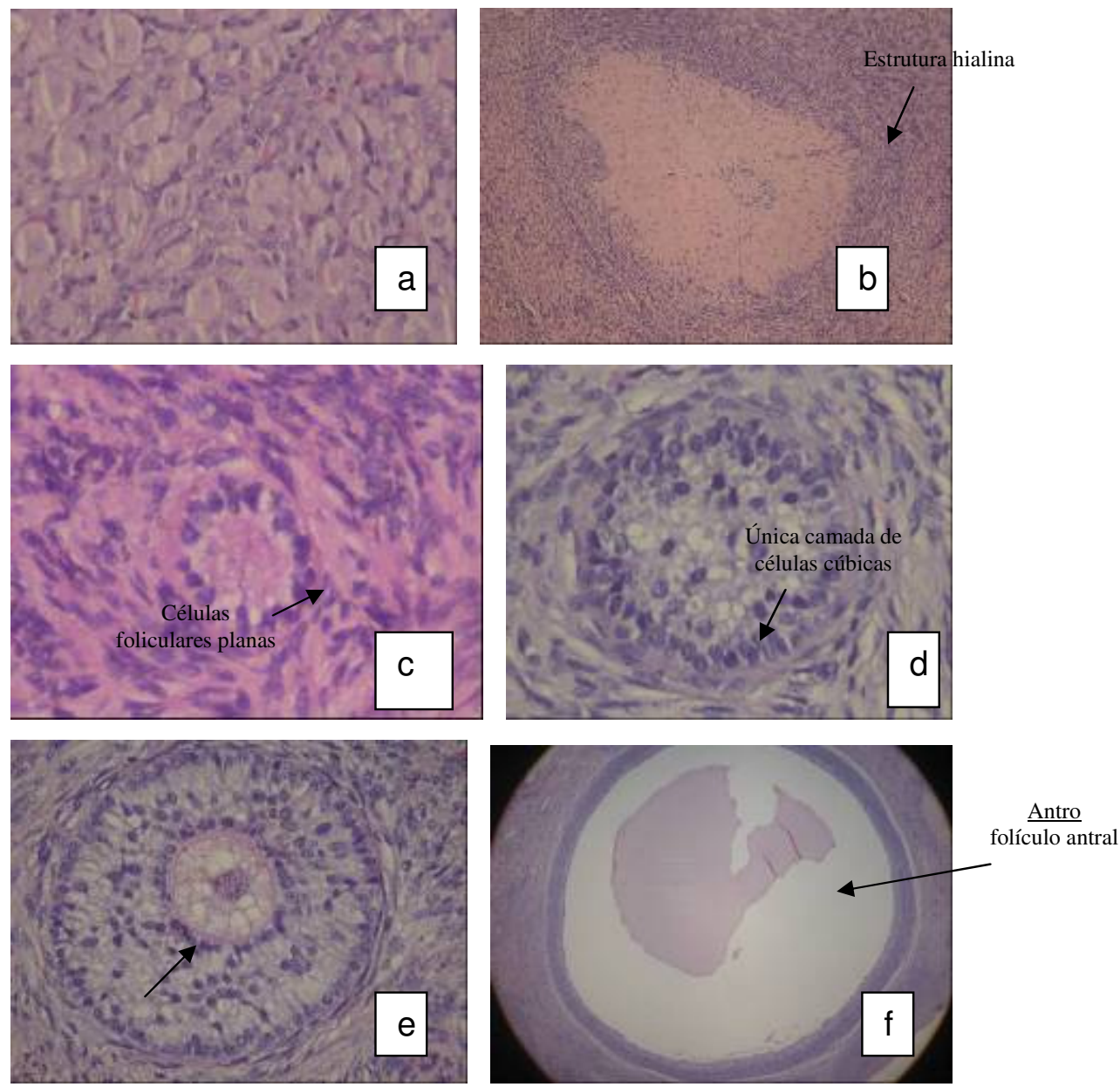

Figura 9: Estruturas encontradas nos cortes histológicos dos tecidos ovarianos:

a) $\mathrm{CL}$ (aumento de $4 \mathrm{x}$ ); b) estrutura hialina (cicatriz) no aumento de 10x; c) folículo primordial (aumento de 40x); d) folículo primário (aumento de 40x); e) folículo secundário com oócito circundado pela zona pelúcida (seta) - aumento de 20x; f) folículo antral (aumento de $4 x)$. 
SOUZA, S.M.P. et al. Avaliação morfológica das estruturas ovarianas em fêmeas bovinas zebuínas durante o ciclo estral. PUBVET, Londrina, V. 8, N. 7, Ed. 256, Art. 1695, Abril, 2014.

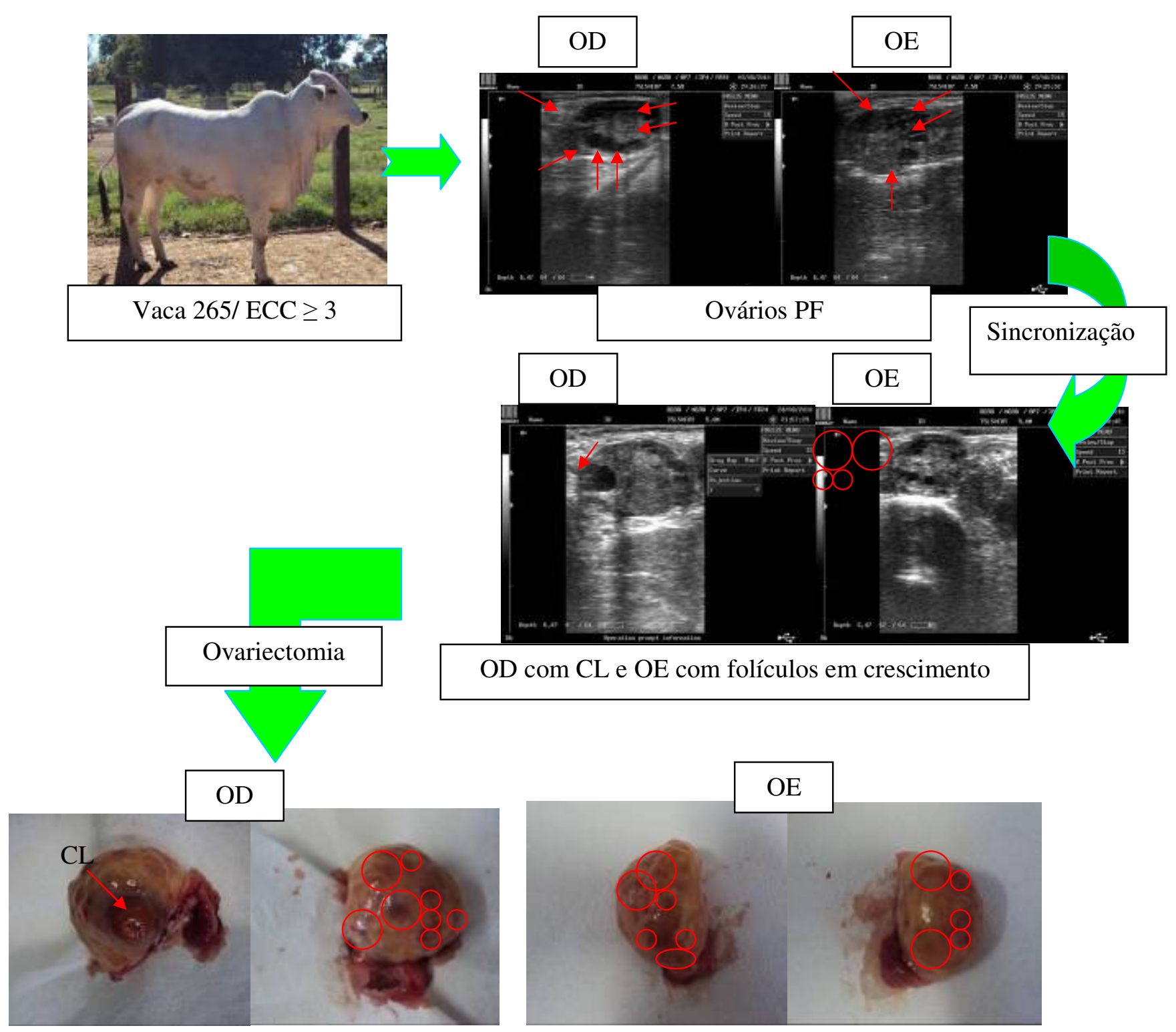

Figura 10: Imagens obtidas da vaca 265 durante as diversas etapas do experimento. 
SOUZA, S.M.P. et al. Avaliação morfológica das estruturas ovarianas em fêmeas bovinas zebuínas durante o ciclo estral. PUBVET, Londrina, V. 8, N. 7, Ed. 256, Art. 1695, Abril, 2014.
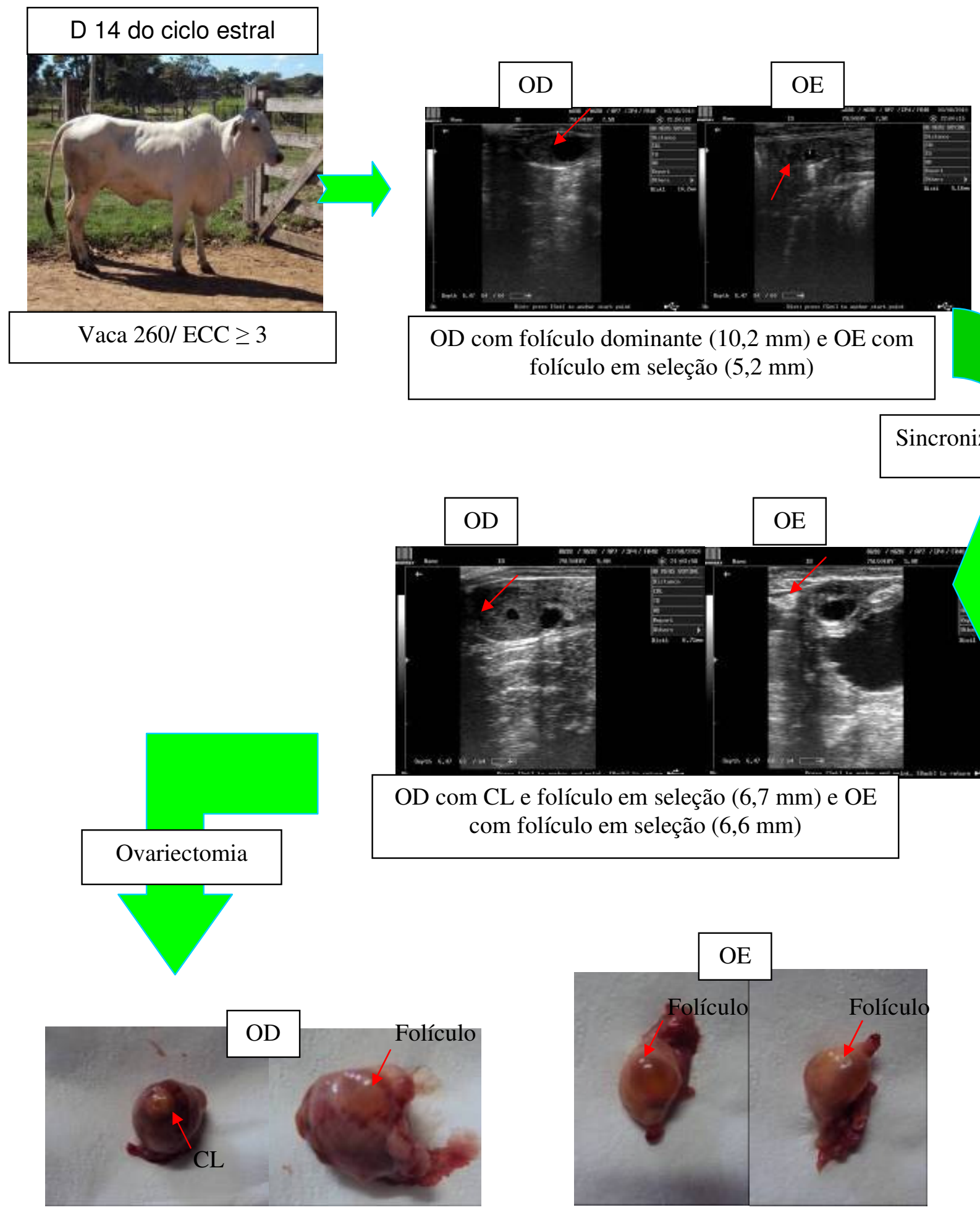

Figura 11: Imagens obtidas da vaca 260 durante as diversas etapas do experimento. 
SOUZA, S.M.P. et al. Avaliação morfológica das estruturas ovarianas em fêmeas bovinas zebuínas durante o ciclo estral. PUBVET, Londrina, V. 8, N. 7, Ed. 256, Art. 1695, Abril, 2014.

A vaca referente ao dia 11 do ciclo estral, antes da sincronização, mostrou os ovários polifoliculares, portando não sendo possível a classificação em que fase da dinâmica folicular ovariana se encontrava. Contudo, posteriormente à sincronização, o ovário direito apresentou um $\mathrm{CL}$, estrutura formada após a ovulação e pequenos folículos em crescimento; já o ovário esquerdo apresentou somente vários folículos em crescimento. E o animal referente ao dia 14 do ciclo estral, antes da sincronização, apresentou o ovário direito com folículo dominante e o ovário esquerdo com folículo em seleção, podendo, portanto, ocorrer a ovulação se os níveis de progesterona estiverem baixos; após a sincronização, o ovário direito apresentou um $\mathrm{CL}$ e folículos em seleção e o ovário esquerdo mostrou-se com folículos também em fase de seleção.

Os resultados obtidos condizem com os descritos na literatura, pois o surgimento da onda ocorreu no período do dia 11 do ciclo estral, retratando assim, o aparecimento de vários folículos de pequeno diâmetro na imagem ultrasonográfica e no dia 14 já há uma seleção folicular. Alguns autores retratam que em ciclos com duas ondas foliculares a detecção da 1a e 2a ondas ocorreu nos dias $0 \pm 0$ e 9,85 $\pm 1,74$ do ciclo estral, resultados esses relatados por Ginther et al. (1989), Taylor \& Rajamahendran (1991), Hamilton et al. (1995) e Figueiredo et al. (1996). Nos ciclos com três ondas foliculares, o surgimento da $1 a, 2 a$ e $3 a$ ondas de crescimento ocorreu nos dias $0 \pm 0$; $10,33 \pm 3,98$; e $16,83 \pm 4,66$ do ciclo estral, respectivamente, sendo relatados por Kastelic (1994) e Borges (1999).

Vale ressaltar que ambas as vacas tiveram o $C L$ no $O D$, ou seja, ambas ovularam no OD e o OE dos dois animais continuou com a dinâmica folicular normalmente; coerente com a maior frequência de ovulações relatadas no ovário direito em bovinos. Para Jainudeen \& Hafez (1995), a ovulação em vacas ocorre mais frequentemente no ovário direito $(60,0 \%)$ que no ovário esquerdo (40,0\%). Relatos de Hasler et al. (1987) indicaram diferença de $57,0 \%$ para o ovário direito e 43,0\% para o esquerdo; Demczu et al. (1998), Viana et al. (1999) e Spell et al. (2001) observaram 64,0\%; 57,1\% e 60,0\% 
SOUZA, S.M.P. et al. Avaliação morfológica das estruturas ovarianas em fêmeas bovinas zebuínas durante o ciclo estral. PUBVET, Londrina, V. 8, N. 7, Ed. 256, Art. 1695, Abril, 2014.

para o lado direito e 36,0\%; $42,9 \%$ e $40,0 \%$ para o lado esquerdo respectivamentes (não existe discussão destes resultados apresentados).

\section{6- Anestro Vs. Não ovulação}

Duas das fêmeas que entraram no programa experimental se encontravam em anestro nutricional, entretanto dos oito animais cíclicos e sincronizados, somente duas vacas ovularam. Por isso, torna-se interessante realizar uma comparação entre esses animais em anestro e as que não ovularam, para dessa forma, analisar os ovários e as estruturas encontradas; abaixo será ilustrada nas figuras 12 e 13 uma sequência ilustrativa comparativa dessas duas situações mencionadas, contudo, dos animais que não ovularam, foi realizado uma média dos resultados obtidos.

Wiltbank et al. (2002), diz que a presença de ovários pequenos, com ausência de corpo lúteo é um sinal que caracteriza o anestro, sendo uma das possíveis causas de anestro a má nutrição, refletida na condição corporal do animal.

Normalmente, o anestro é consequência de uma série de folículos dominantes que falham em ovular, devido a baixas concentrações de LH (ROCHE et al. 1992; JOLLY et al. 1995); visto que os animais classificados em anestro nutricional, ao exame histológico, apresentaram uma considerável quantidade de folículos terciários.

Contudo, as vacas que não ovularam, também apresentaram um considerável número de folículos terciários somado a uma quantidade superior de estruturas superficiais nos ovários quando comparados aos animais 261 e 263; entretanto, também não apresentaram $C L$ e, com isso, não se pode predizer ao certo o motivo desses animais não terem ovulado, pois se encontravam em bom estado nutricional e conseqüente condição corporal. 
SOUZA, S.M.P. et al. Avaliação morfológica das estruturas ovarianas em fêmeas bovinas zebuínas durante o ciclo estral. PUBVET, Londrina, V. 8, N. 7, Ed. 256, Art. 1695, Abril, 2014.

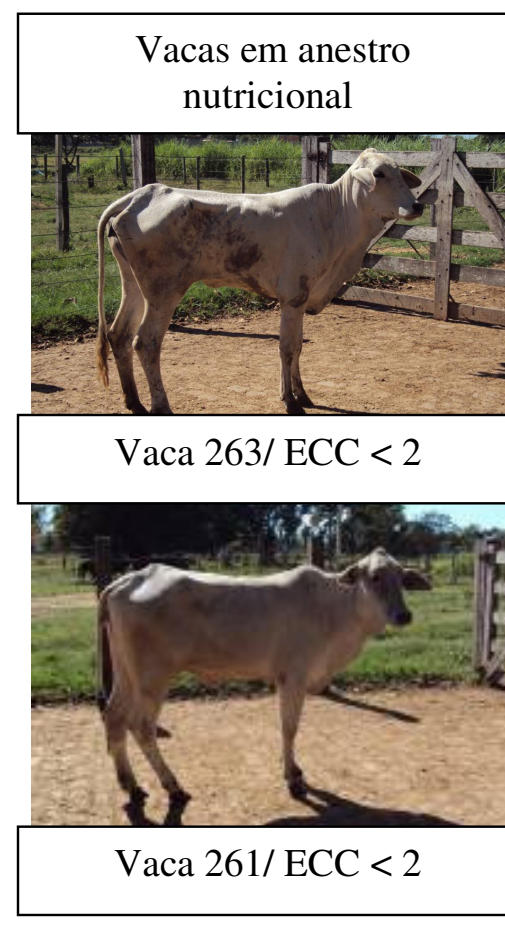

Ovários lisos, com poucas estruturas superficiais, com média de comprimento 2,5

$\mathrm{Cm}$ e largura de 2,0 Cm
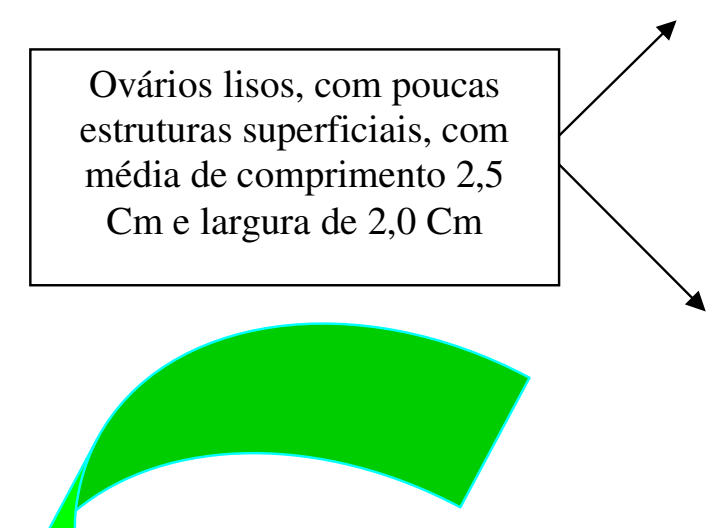

OD com dois folículos pequenos e OE com maior folículo de 4,9 $\mathrm{mm}$
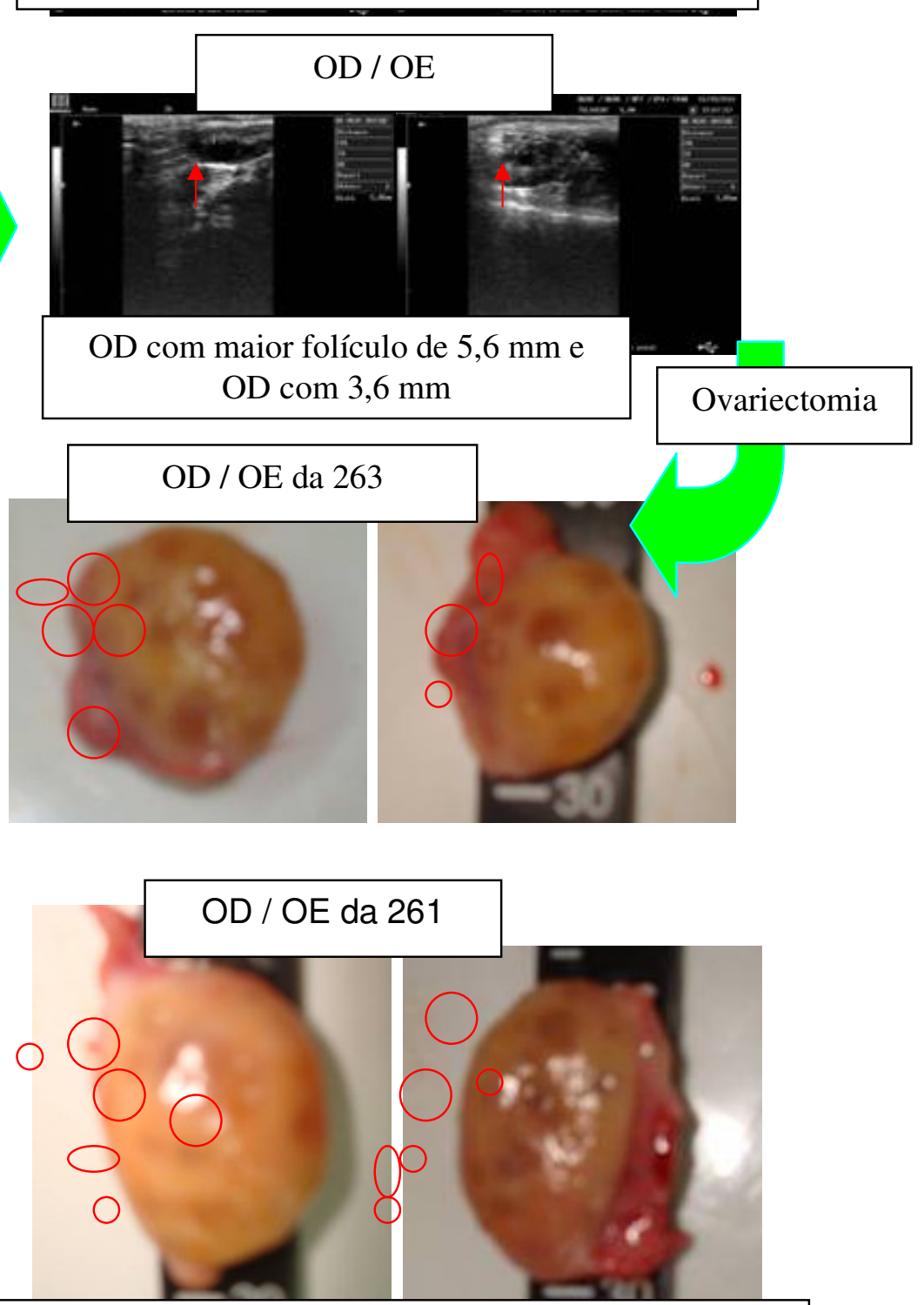

Histologicamente: apresentaram muitas estruturas, principalmente folículos primordiais, o que caracteriza o surgimento de novas ondas foliculares; entretanto também havia muita estrutura hialina, contudo não é possível distinguir a origem dessa estrutura, pois essas vacas também passaram por três sessões de punção folicular guiada por ultrassom. 
SOUZA, S.M.P. et al. Avaliação morfológica das estruturas ovarianas em fêmeas bovinas zebuínas durante o ciclo estral. PUBVET, Londrina, V. 8, N. 7, Ed. 256, Art. 1695, Abril, 2014.

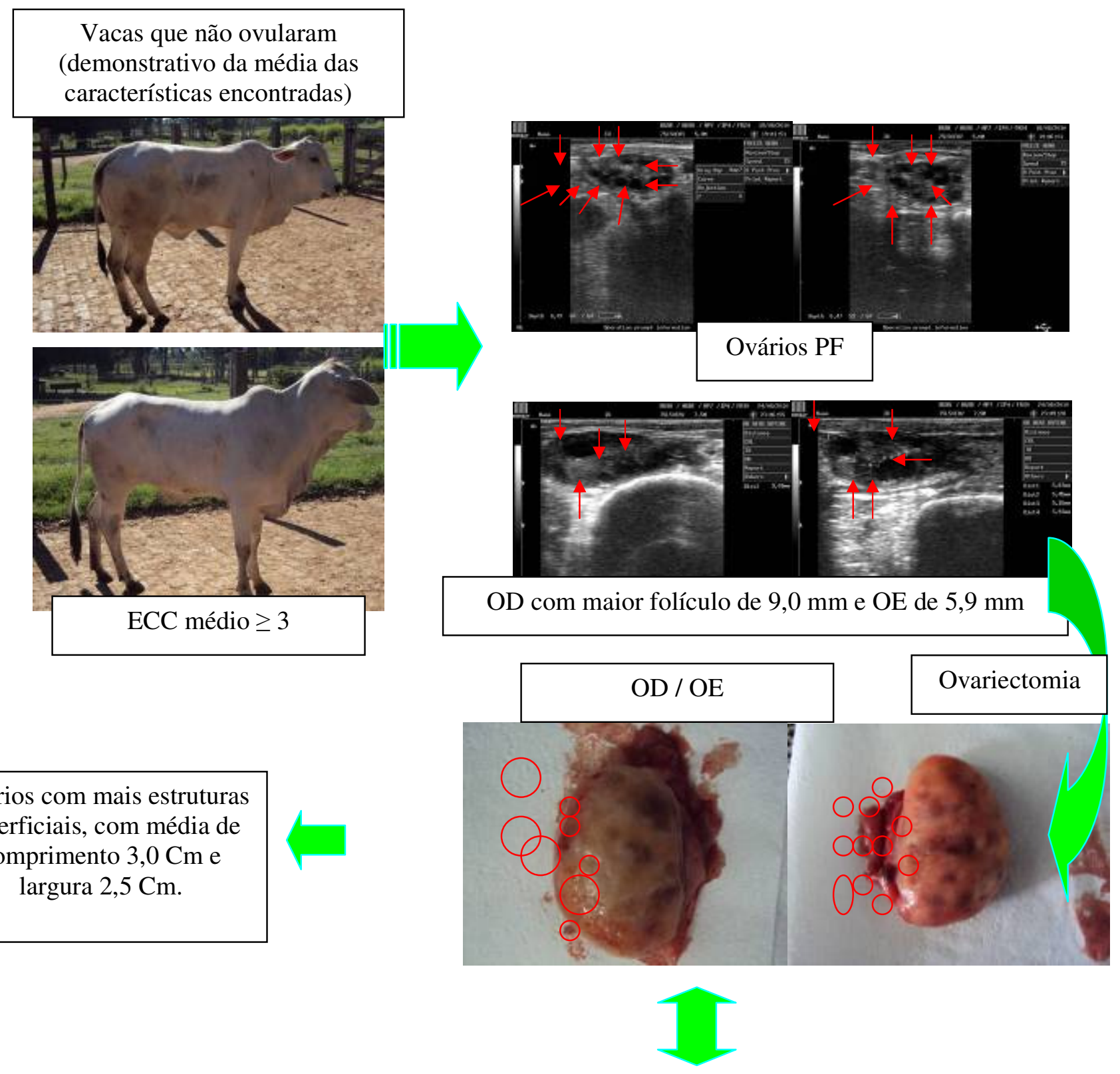

Ovários com mais estruturas superficiais, com média de comprimento $3,0 \mathrm{Cm}$ e largura $2,5 \mathrm{Cm}$.

Histologicamente: apresentaram todas as estruturas, mas folículos primordiais em menor quantidade do que as vacas em anestro; entretanto também havia muita estrutura hialina, contudo não é possível distinguir a origem dessa estrutura, pois essas vacas também passaram por três sessões de punção folicular guiada por ultrassom.

Figura 13: Sequência ilustrativa das estruturas encontradas nos ovários das fêmeas que não ovularam. 
SOUZA, S.M.P. et al. Avaliação morfológica das estruturas ovarianas em fêmeas bovinas zebuínas durante o ciclo estral. PUBVET, Londrina, V. 8, N. 7, Ed. 256, Art. 1695, Abril, 2014.

\section{Conclusões}

> Os resultados ultrassonográficos, macroscópicos e microscópicos obtidos, condizem com o descrito na literatura, tanto para os animais com ECC $\geq$ 3, quanto para os com ECC $<2$.

> As estruturas hialinas, provavelmente, originam-se da cicatriz ocasionada pelas punções foliculares que os animais foram submetidos; entretanto, observou-se que não houve interferência na foliculogênese.

\section{Referencias Bibliográficas}

ADONA, P. R. Bloqueio da meiose com Butirolactona I em ovócitos bovinos: efeitos sobre a maturação nuclear e citoplasmática. 2006. 78p. Tese (Doutorado em Produção Animal) - Centro de Ciências e Tecnologias Agropecuárias, Universidade Estadual do Norte Fluminense, Campos dos Goytacazes.

ALbuQuerque, K. P.; MARQUeS, J. A.; PRADO, I. N.; KUTSUNUGI, E.; MACEDO, R. M. G. Morfologia ovariana em novilhas bubalinas terminadas em confinamento em função do uso de promotor de crescimento ou esferas de chumbo no utero. Acta Scientiae Veterinariae, v. 26, no. 2, p. 223-240. 2004.

ALVAREngA, M. A. Ciclo estral eqüino - Dinamica folicular e controle endocrino. Disponível em: <WWW.equalli.com.br/upload/textos/ pdf/prt/472.pdf>. Acesso em: $10 / 01 / 2010$.

ALVES, N. G.; COSTA, E. P.; GUIMARAES, J. D.; SILVA, M. R.; ZAMPERLINI, B.; COSTA, F. M. J.; SANTOS, A. D. F.; MIRANDA NETO, T. Atividade ovariana em fêmeas bovinas da raça holandesa e mestiças holandês $X$ zebu, durante dois ciclos estrais normais consecutivos. Revista Brasileira de Zootecnia, v. 31, n. 2, p. 627 - 634. 2002.

BARRETA, M. H. O efeito da Angiotensina II na maturação nuclear de oocitos bovinos e mediado pelas prostaglandinas E2 e F2a. 2008. 61p. Dissertação (Mestrado na área de Concentração em Fisiopatologia da Reprodução) - Programa de pós-graduação em Medicina Veterinária, Universidade Federal de Santa Maria, Santa Maria.

BENEDETTI, E., SILVA, H.S. Influencia da condição corporal na produção de leite, consumo e desempenho reprodutivo de vacas leiteiras. Vet. Not. Uber. v.3, n.1, p.175-183. 1997.

BERTAN, C. M.; BINELLI, M.; MADUREIRA, E. H.; TRALDI, A. S. Mecanismos endócrinos e moleculares envolvidos na formação do corpo lúteo e na luteolise - revisão de literatura. Braz. J. Vet. Res. Anim. Sci., Sao Paulo, v. 43, n. 6, p. 824 - 840. 2006.

BOLS, P. E. J.; LEROY, J. L. M. R.; VIANA, J. H. M. Aspectos técnicos e biológicos na recuperação de oocitos via trans-vaginal guiada por ultra-som em vacas. Acta Scientiae Veterinariae, 33 (supl. 1): 103-118. 2005. 
BORGES, A. M. Dinâmica folicular e superovulação em novilhas mestiças tratadas com somatotropina bovina (rBST) e efeito da temperatura na qualidade dos embriões. Viçosa, MG: Universidade Federal de Viçosa, 1999. 100 p. Dissertação (Mestrado em Zootecnia).

BRAUN, R.K. Analysis of reproductive records using DHIA summaries and other monitors in large dairy herds. In: MORROW, D.A. Current therapy in theriogenology. s/ed. Philadelphia, PA: W. B. Saunders Company. p.414- 418. 1986.

BURATINI JR, J.; CASTILHO, A. C. S.; TEIXEIRA, A. B.; COSTA, I. B.; PINTO, M. G. L.; GIOMETTI, I. C.; GLAPINSKI, V. F.; NOGUEIRA, M. F. G.; BARROS, C. M.; PRICE, C. A. Avancos no entendimento da fisiologia do desenvolvimento folicular. Acta Scientiae Veterinariae, 33 (supl 1): 55-68. 2005.

BURATINI JR, J. Foliculogenese em bovinos. In: II SIMPOSIO INTERNACIONAL DE REPRODUCAO ANIMAL APLICADA- Reprodução de Bovinos, 2, 2006. Anais, Paraná, p.55-62.

CAIXETA, E. S.; DODE, M. A. N. Dissecação folicular: um método eficiente para estudos de competência ovocitaria. Embrapa Recursos Genéticos e Biotecnologia. 2008. 21p. (Embrapa Recursos Genéticos e Biotecnologia. Documentos, 260).

CAMPOS JR, P. H. A.; ASSUNPCAO, C. M.; VIANA, J. H. M. Foliculogenese: da migração das células germinativas primordiais a aplicação de tecnologias reprodutivas em mamíferos. CES revista, v. 23, p. $35-44.2009$.

CASTILHO, O. A. C., MARQUES JUNIOR, A.P. Condição corporal de vacas Holandesas no período seco e no inicio de lactação. Vet. Not. Uber. v.3, n.1, p.107-111. 1997.

CHACUR, M. G. M.; VALENTIM, N. C.; OBA, E.; KRONKA, S. N. Correlações da morfometria ovariana e hormonais de progesterona e cortisol em vacas zebus não prenhes. Ciência Animal Brasileira, v. 10, n. 3, p. 870 - 878. 2009.

COSTA, A. A. Hormônios do ciclo menstrual e corpo lúteo. Disponível em: <http://pt.shvoong.com/medicine-and-health/1620643-horm\%C3\%B4nios-ciclo - menstrualcorpo- $1 \%$ C3\%BAteo/>. Acesso em: 14 set, 2010.

COSTA, I. B. Fatores homólogos aos fatores de crescimento fibroblasticos são expressos em folículos antrais e corpos lúteos bovinos. 2008. 110p. Tese (Doutorado em Medicina Veterinária, Área de Reprodução Animal) - Faculdade de Medicina Veterinária e Zootecnia, Universidade Estadual Paulista "Julio de Mesquita Filho", Botucatu.

DEMCZUK, E.; KOZICKI, L. E.; PONTELLI, E. S.; SALLES, J. O. Transferência de embrião em vacas da raça Simental na região noroeste do Paraná e Sul do Mato Grosso do Sul. Brazilian Journal of Veterinary Research and Animal Science, v. 35, n. 4, p. 174-177. 1998.

FERNANDES, P. Expressão dos transcritos do receptor de LH em células da granulosa de fêmeas Nelore submetidas ou não a super-estimulação ovariana. 2008. 86 p. Tese (Doutorado em Medicina Veterinária, Área de Reprodução Animal) - Faculdade de Medicina Veterinária e Zootecnia, Universidade Estadual Paulista "Julio de Mesquita Filho", Botucatu.

FERREIRA, A. M. Efeito da amamentação e do nível nutricional na atividade ovariana de vacas mestiças leiteiras. Viçosa, MG: UFV. 1990. 133p. Dissertação (Doutorado em Zootecnia) - Universidade Federal de Viçosa. 1990. 
FERREIRA, A. M. Manejo reprodutivo e sua importância na eficiência da atividade leiteira. Coronel Pacheco - MG, Embrapa Gado de Leite. 1991. 47p. (Documentos n. 46).

FERREIRA, A. M.; VIANA, J. H. M.; CAMARGO, L. S. A.; SA, W. F.; PEREIRA, P. A. C. População Folicular Ovariana Durante o Ciclo Estral em Vacas da Raça Gir. Revista Brasileira de Zootecnia, v. 33, n. 6, p. 1689 - 1694. 2004 (supl. 1).

FIGUEIREDO, J. R.; RODRIGUES, A. P. R.; SANTOS, R. R.; LOPES, C.; SILVA, J. R. V. Estado atual da Biotecnicas de manipulacao de oocitos inclusos em foliculos pre-antrais. Acta Scientiae Veterinariae, v. 34 (supl 1), p. 71 - 84. 2006.

FIGUEIREDO, J. R.; CELESTINO, J. J. H.; RODRIGUES, A. P. R.; SILVA, J. R. V. Importancia da biotécnica de MOIFOPA para o estudo da foliculogenese e produção in vitro de embriões em larga escala. Revista Brasileira de Reprodução Animal, v. 31, n. 2, p. 143 - 152. 2007.

Figueiredo, M. M. N.; FOnSECA, F. A.; TORRES, C. A. A.; GALimberti, A. M.; ALMeidA, C. D. Dinâmica Folicular Ovariana de Vacas Leiteiras no Pós-Parto apos Tratamento com Buserelina (GnRH) e Cloprostenol (PGF2a). Revista Brasileira de Zootecnia, v. 29 (3): 725 - 731.2000.

FIGUEIREDO, R. A.; BARROS, C. M.; PINHEIRO, O. L. et al. Ovarian follicular dynamics in Nelore breed (Bos taurus indicus) cattle. Theriogenology, v.47, p.1489-1505. 1996.

Fisiologia da Reprodução. Disponível em: <http:// www.foa.unesp.br/ pesquisa/ centros_e_nucleos/zootecnia/informacoestecnica/bovinocultura/Fisiologia\%20da\%20reprodu\% C3\%A7\%C3\%A30.pdf>. Acessado em: 15/12/2009.

GONCALVES, P. B. D.; FIGUEIREDO, J. R.; FREITAS, V. J. F. Biotecnicas aplicadas a Reproducao Animal. In: FIGUEIREDO, J. R.; RODRIGUES, A. P. R.; AMORIM, C. A.; SILVA, J. R. V. Manipulacao de Oocitos Inclusos em Folículos Ovarianos Pre-antrais, 2. Ed. Sao Paulo: Roca, 2008. p. $303-327$.

GONCALVES, P. B. D.; FIGUEIREDO, J. R.; FREITAS, V. J. F. Biotecnicas aplicadas a Reprodução Animal. In: GONCALVES, P. B. D.; OLIVEIRA, M. A. L.; MEZZALIRA, A.; MONTAGNeR, M. M.; VISINTIN, J. A.; COSTA, L. F. S. Produção In Vitro de Embriões, 2. Ed. Sao Paulo: Roca. 2008. p. $261-291$.

GONCALVES, P. B. D.; FIGUEIREDO, J. R.; FREITAS, V. J. F. Biotecnicas aplicadas a Reprodução Animal. In: MORAES, J. C. F.; SOUZA, C. J. H.; GONCALVES, P. B. D.; FREITAS, V. J. F.; LOPES JR, E. S. Controle do Estro e da Ovulação em Ruminantes, 2. Ed. São Paulo: Roca. 2008. p. 33 - 56.

GONCALVES, P. B. D.; FIGUEIREDO, J. R.; FREITAS, V. J. F. Biotécnicas aplicadas a Reprodução Animal. In: NEVES, J. P.; NUNES, J. F.; MORAES, J. C. F.; SOUZA, C. J. H.; SALGUEIRO, C. C. M.; ALMEIDA, J. L. Inseminação artificial em pequenos ruminantes, 2. Ed. Sao Paulo: Roca. 2008. p. 83 - 103.

GUIDO, M. C. Endocrinologia da Reprodução. Net São Paulo. 2005. Seção Endocrinologia. Disponivel em: <http://www.mcguido. vet.br/endocrinologia.htm>. Acesso em: 18/12/2009.

GUIDO, M. C. Foliculogenese. Net São Paulo. 2005. Seção Foliculogenese. Disponivel em: <http://www.mcguido.vet. br/foliculogenese.htm>. Acesso em: 18/12/2009. 
GINTHER, J.O.; KNOPF, L.; KASTELIC, J.P. Temporal association among events in cattle during o estrous cycle with two or three follicular waves. Journal of Reproduction and Fertility, v.87, p.223-230. 1989.

GURGEL, J. R. C.; VIANA, C. H. C.; PEREZ, E. G. A.; NICHI, M. Dinâmica folicular em eguas: aspectos intrafoliculares. Revista Brasileira de Reprodução Animal, v. 32, n. 2, p. 122132. 2008.

HAMILTON, S.A.; GARVERICK, H.A.; KEISLER, D.H. et al. Characterization of ovarian follicular cysts and associated endocrine profiles in dairy cows. Biology of Reproduction, v.53, p.890898. 1995.

HASLER, J. F.; MCCAULEY, A. D.; LATHROP, W. F.; FOOTE, R. H. Effect of donor-embryorecipient interactions SPANO, A. A.; SILVA, A. A. M. R. Níveis plasmáticos de progesterona durante o ciclo estral e na fase inicial da gestação em bovinos da raça Holandesa (Bos taurus taurus). Ars Veterinaria, v. 8, p. 131- 141. 1992.

IRELAND, J.J., MURPHEE, R.L., COULSON, P.B. Accuracy of predicting stages of bovine estrous cycle by gross appearance of the corpus luteum. J. Dairy Sci., v.63, p. 155-160. 1980.

JAINUDEEN, M. R., HAFEZ, E. S. E. Bovinos e bubalinos. In: HAFEZ, E. S. E. Reprodução animal. Sao Paulo: Manole, 1995. p. 319-334.

JOLLY, P.D.; MCDOUGALL, S.; FITZPATRICK, L.A.; MACMILLAN, K.L.; ENTWISTLE, K.W. Physiologiacl effects of under nutrition on postpartum anoestrum in cows. Journal of Reproduction and Fertility, v. 49, p. 477-92. 1995.

KASTELIC, J.P.; KO, J.C.H.; GINTHER, O.J. Suppression of dominant and subordinate ovarian follicles by a proteinaceous fraction of follicular fluid in heifers. Theriogenology, v.34, p.499509. 1990.

LEAL, C. L. V.; ADONA, P. R. O bloqueio meiótico e a maturação in vitro. Acta Scientiae Veterinariae, v. 34 (supl 1), p. 131-144. 2006.

LEAL, L. S. Estudo morfofisiometrico de ovários e maturação ovocitaria in vitro em bubalinos e bovinos nas diferentes fases da atividade reprodutiva. 2008. 180p. Tese (Doutorado em Reprodução Animal) - Faculdade de Medicina Veterinária e Zootecnia, Universidade Estadual Paulista, Botucatu.

LEON, P. M. M.; SANTOS, E. C. S.; RAMBO, G.; LUCIA JR, T.; DESCHAMPS, J. C. Efeito da suplementação de Cisteamina ao meio de maturação in vitro de oocitos eqüinos. In: Congresso de Iniciação Cientifica, 16. 2007. Pelotas. Disponível em:<http://www.ufpel.tche.br/ cic/2007/cd/pdf/CA/CA_01811.pdf>. Acesso em: 15/01/2010.

MACEDO, D. B. Dinâmica folicular ovariana em fêmeas bovinas Bos indicus. 2008. 16p. Seminário I apresentado no Programa de pós-graduação em Ciência Animal. Faculdade de Medicina Veterinária e Zootecnia, Universidade Federal do Mato Grosso do Sul, Campo Grande. Disponível em: <http://www.mca.ufms.br/producao/seminarios/2008/ Dinamica_folicula_ovaria na.pdf>. Acessado em: 19/12/2009.

MACHADO, M. F. Expressão dos fatores de crescimento fibroblastico 17 e 18 (FGF-17 e FGF-18) em folículos antrais bovinos. 2008. 104p. Dissertação (Mestre na área de Reprodução Animal) - Faculdade de Medicina Veterinária e Zootecnia, Universidade Estadual Paulista, Botucatu. 
MARTIN, I.; FERREIRA, J. C. P. Fisiologia da ovulação e da formação do corpo lúteo bovino. Vet. e Zootec., v. 16, n. 2, p. 270 - 279. 2009.

MATOS, M. H. T.; SILVA, J. R. V.; RODRIGUES, A. P. R.; FIGUEIREDO, J. R. Técnicas para avaliação da qualidade de folículos ovarianos pre-antrais cultivados in vitro. Revista Brasileira de Reprodução Animal, v. 31, n. 4, p. 433 - 442. 2007.

MELO, D. S. Produção in vitro de embriões derivados de oocitos obtidos em diferentes fases de onda folicular. 2007. 42p. Tese (Doutorado em Reprodução Animal) - Faculdade de Medicina Veterinária e Zootecnia, Universidade Estadual Paulista, Botucatu.

MELO, L. C. Dinâmica folicular de vacas de corte tratadas com três protocolos de sincronização da ovulação. 2009. 41p. Dissertação (Mestre em Ciências Veterinárias na área de Reprodução Animal) - Faculdade de Veterinária, Universidade Federal do Rio Grande do Sul, Porto Alegre.

MINGOTI, G. Z. Aspectos técnicos da produção in vitro de embriões bovinos: importância na maturação in vitro. Net Bauru, out. 2007. Secao artigos. Disponivel em: <http://www.bioembryo.com.br/noticias. php? cat=1\&subcat=2\&id=133>. Acesso em: 21 fev. 2010.

MOLINA, L. Anestro em bovinos: mecanismos e tratamento (Parte III). Net Belo Horizonte, jul, 2005. Seção artigos técnicos. Disponível em: <http://www.rehagro.com.br/siterehagro/ publicacao.do?cdnoticia=1007>. Acesso em: 15 out. 2010.

NEVES, M. M.; MARQUES JR., A. P. Proporção volumétrica dos constituintes do corpo luteo de Nelore. Arq. Bras. Med. Vet. E Zootec., v. 58, n. 5, p. 944-946. 2006.

PAVAO, G. D. Viabilidade da Produção In Vitro de Embriões Ovinos em Meio de Maturação Suplementado com Soro Fetal Bovino (SFB) ou Albumina Sérica Bovina (BSA) Acrescido ou não de Cisteamina. 2009. 64p. Dissertação (Mestre em Reprodução Animal) - Faculdade de Medicina Veterinária e Zootecnia, Universidade Estadual Paulista, Botucatu.

PINTO, Cristina Maria Henrique. Fisiologia do Sistema Endócrino e aplicações clinicas. Disponível em: <http://www.cristina.prof.ufsc.br>. Acesso em: 10/01/2010.

ROCHE, J.F.; CROWE, M.A.; BOLAND, M.P. Pospartum anoestrus in dairy and beef cows. Animal Reproduction Science, v. 38, p. 371-8. 1992.

SADLER, T. W. Embriologia Médica com Orientación Clinica. In: SADLER, T. W. Primera semana de desarrollo: de la ovulación a la implantación, 8. Ed. Buenos Aires, Bogotá, Caracas, Madrid, México, São Paulo: Panamericana, 2001. p. 30-47.

SANDRI, L. R. Efeito de Bloqueadores Meióticos na Maturação e Ultraestrutura de oocitos e sua conseqüência na Produção de Embriões In Vitro. 2007. 58p. Dissertação (Mestre em Fisiopatologia da Reprodução Animal) - Centro de Ciências Rurais, Universidade Federal de Santa Maria, Santa Maria.

SANTOS, R. R.; CELESTINO, J. J. H.; LOPES, C. A. P.; MELO, M. A. P.; RODRIGUES, A. P. R.; FIGUEIREDO, J. R. Criopreservação de folículos ovarianos pre-antrais de animais domésticos. Revista Brasileira de Reprodução Animal, v. 32, n. 1, p. 9-15. 2008.

SENEDA, M. M.; BORDIGNON, V. Novos conceitos de foliculogenese. Acta Scientiae Veterinariae, v. 35, n. 3, p. 857-868. 2007. 
SILVA, D. E. R. C. Recuperação de Ovócitos em bovinos. 2006. 32p. Monografia (Especialista em Produção e Reprodução de Bovinos) - Universidade Castelo Brando, Rio de Janeiro.

SPELL, A. R.; BEAL, W. E.; CORAH, L. R.; LAMB, G. C. Evaluating recipient and embryo factors that affect pregnancy rates of embryo transfer in beef cattle. Theriogenology, v. 56, p. 287297. 2001.

TAYLOR, C.; RAJAMAHENDRAN, R. Follicular dynamics, corpus luteum growth and regression in lactating dairy cattle. Canadian Journal of Animal Science, v.71, p.61-68. 1991.

TECNOPEC. Net São Paulo, 2008. Seção Manuais de animais. Disponível em: <http://www.tecnopec.com.br/download. php?f=453d3138d2a55ca7fddc0374988effc6>. Acesso em: 08/02/2010.

VARAGO, F. C.; MENDONCA, L. F.; LAGARES, M. A. Produção in vitro de embriões bovinos: estado da arte e perspectiva de uma técnica em constante evolução. Revista Brasileira de Reproducao Animal, v. 32, n. 2, p. 100-109. 2008.

VIANA, J. H. M.; FERREIRA, A. M.; SA, W. F.; CAMARGO, L. S. A. Características morfológicas e funcionais do corpo lúteo durante o ciclo estral em vacas da raça Gir. Arquivo Brasileiro de Medicina Veterinária e Zootecnia, v. 51, n. 3, p. 251-256. 1999.

VIANA, J. H. M.; NASCIMENTO, A. A.; PINHEIRO, N. L.; FERREIRA, A. M.; CAMARGO, L. S. A.; SA, W. F.; MARQUES JUNIOR, A. P. Caracterização de seqüelas subseqüentes a punção folicular em bovinos. Pesq. Vet. Bras. 2003.

WEBB, R.; DUGAN, R. L.; QUINN, A.; FOULADI-NASHTA, A. A.; HUNTER, M. G. Desenvolvimento folicular em espécies mono e poli-ovulatorias: do feto a fertilização. Acta Scientiae Veterinariae, v. 34 (supl. 1), p. 95-114. 2006.

WILTBANK, M.C., A. GUMEN, AND R. SARTORI. Physiological classification of anovulatory conditions in cattle. Theriogenology. v. 57, p. 21-52. 2002.

WIKIPEDIA. Net, dez, 2009. Seção artigos. Disponível em: <http://pt.wikipedia.org/wiki/ Ov\%C3\%B3cito>. Acesso em: 08/02/2010. 